\title{
UM PASSO EM DIREÇÃO A UM \\ SISTEMA DE INFORMAÇÃO DE NASCIDOS VIVOS \\ DE MÚLTIPLA INTERFACE
}

Fernando Flores Santos Ribeiro

Tese de Doutorado apresentada

ao Departamento de Epidemiologia

da Faculdade de Saúde Pública

da Universidade de São Paulo

para a obtenção do Grau de Doutor

Área de Concentração:

Epidemiologia

Orientadora: Prof ${ }^{\mathrm{a}}$. Dr ${ }^{\mathrm{a}}$. Márcia

Furquim de Almeida

São Paulo

2003 


\section{AGRADECIMENTOS}

Os meus sinceros agradecimentos à Prof ${ }^{\mathrm{a}}$. Dr ${ }^{\mathrm{a}}$. MÁRCIA FURQUIM DE ALMEIDA por sua orientação prestada com paciência e entusiasmo contagiante

A minha prima ZILDA VICTÓRIA MACEDO DA COSTA PINHO, por seu apoio e cuidados durante minhas estadias em São Paulo.

A meus pais CLÉLIO RIBEIRO DE MACEDO e MARINA FLORES SANTOS RIBEIRO, pelo dom da vida e pelos princípios que me passaram por palavra e exemplo.

A minha querida esposa BIANCA SACRAMENTO FLORES RIBEIRO, por seu apoio, compreensão e afeto. 


\section{RESUMO}

Objetivo. Como os nascidos vivos em domicílio que não são registrados em cartório não são captáveis pelo SINASC (Sistema de Informação de Nascidos Vivos), propõe-se o desenvolvimento e teste de um programa de computador chamado "SINASC - Interface Simplificada" para servir de interface complementar ao SINASC, bem como a criação do formulário DN (Declaração de Nascido Vivo) simplificada a ser aplicado e coletado pelos agentes do PACS (Programa de Agentes Comunitários de Saúde). Métodos. O programa foi criado na linguagem " $\mathrm{C}++$ " através do programa "BORLAND C++ BUILDER 5" com capacidade de exportar seus dados para o SINASC Padrão. Foram obtidos dados sobre os nascidos vivos hospitalares e domiciliares referentes ao período de 01/05/2002 a 31/07/2002 (três meses) coletados por agentes do PACS do município de Ilhéus-BA. Para a realização de uma análise comparativa, foram obtidos na SMS (Secretaria Municipal de Saúde) de Ilhéus os dados do SINASC referentes ao mesmo periodo. Resultados. Foram coletados 170 formulários simplificados válidos e o banco de dados do SINASC Padrão, fornecido pela SMS, com 445 DNs não duplicadas. Das 170 DNs simplificadas, 96 foram identificadas como contribuição não redundante ao banco de dados padrão, representando $17,7 \%$ do total reunido. Conclusões. Foi demonstrada a viabilidade de se utilizar os agentes do PACS para melhorar a cobertura do SINASC, obtendo-se boa qualidade de preenchimento dos formulários. Também foram testadas e aprovadas variáveis alteradas no intuito de melhorar a sua sensibilidade. 


\section{SUMMARY}

Objective. As the not registered born alive in home are not captured by the software SINASC (Born Alive Information System), it is proposed the development and test of a new software called "SINASC - Simplified Interface" to be a complementary interface of SINASC, as well as the creation of the form DN (Born Alive Declaration) simplified to be applied and collected by the agents of PACS (Health Agents Community Program). Methods. The program was created in the language "C++" through the program "BORLAND C++ BUILDER 5" with data exporting capacity for the official SINASC. The forms were obtained for each of the born alive in the period from $01 / 05 / 2002$ to $31 / 07 / 2002$ (three months) collected by PACS agents of the city of Ilhéus-Ba. For the accomplishment of a comparative analysis, they were obtained in the SMS (City Health Department) of Ilhéus the data from the official SINASC to the same period. Results. A total of 170 valid simplified forms were collected and the SINASC official database, supplied by the SMS, with 445 not duplicated DNs. From the 170 simplified DNs, 96 were identified as non-redundant contribution to the official database, representing $17,7 \%$ of the total unified. Conclusions. The viability of using the agents of PACS to improve the covering of SINASC was demonstrated, as well as the good quality of the new forms filling by them. They were also tested and approved altered variables to improve their sensibility. 


\section{LISTA DE FIGURAS}

Figura 1.1 - Fluxo das vias das Declarações de Nascidos Vivos - DNs ..................6

Figura 4.1 - Janela inicial do programa "SINASC - Interface Simplificada". ........ 32

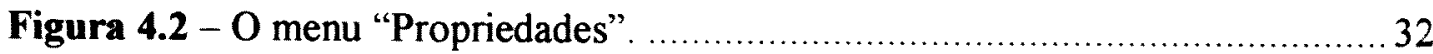

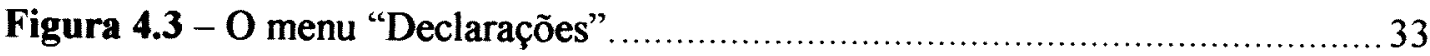

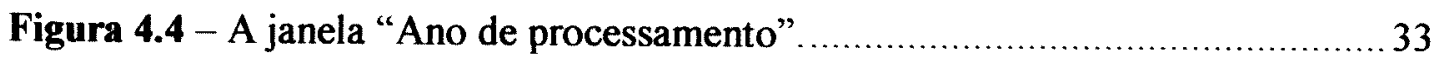

Figura 4.5 - A janela de aviso de criação de uma nova tabela anual. .......................33

Figura 4.6 - O menu "Declarações" após escolha do ano de processamento........... 34

Figura 4.7 - A janela “Inserir DNs" ...................................................... 34

Figura 4.8 - A janela de aviso de duplicação de numeração de DNs. ..................... 35

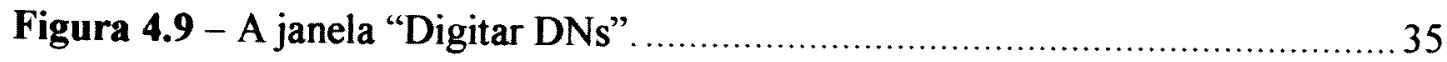

Figura 4.10 - A janela de aviso da inexistência da DN especificada ...................... 35

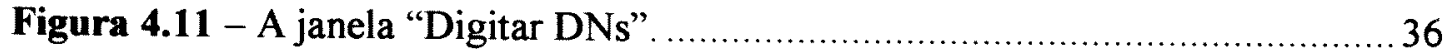

Figura 4.12 - O menu “Operacionais". ....................................................... 38

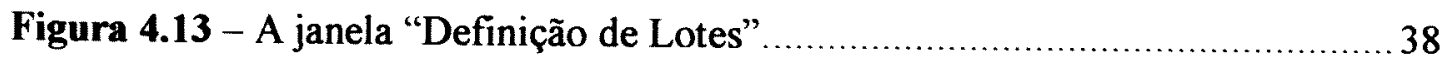

Figura 4.14 - A janela "Exportação para o SINASC Padrão"............................... 39

Figura 4.15 - O submenu “Teste de Duplicidade de DNs" ............................. 41

Figura 4.16 - A janela "Busca de Duplicatas no Banco de Dados" ...................... 42 


\section{LISTA DE TABELAS}

Tabela 1.1: Tipos e Formatos de campos.

Tabela 1.2: Exemplo de definição dos Tipos e Formatos de campos de uma tabela. 15

Tabela 1.3: Exemplo de Tabela de um Banco de Dados especificada pela Tabela 1.2.

Tabela 1.4: Distribuição do número de estabelecimentos de saúde existentes no municipio de Ilhéus, 1999.

Tabela 4.1: Descrição das características dos campos da tabela simplificada do Banco de Dados do "SINASC - Interface Simplificada". (2002 db) (um registro para cada DN - simplificada). 28

Tabela 4.2: Descrição das características dos campos da DNBA2002.DBF (um registro para cada $\mathrm{DN}$ )

Tabela 4.3: Descrição das características dos campos da ADBA2002.DBF (um registro para cada $\mathrm{DN}$ ).

Tabela 4.4: Descrição das características dos campos da CTBA2002.DBF (um registro para cada lote)

Tabela 4.5: Distribuição dos formulários coletados segundo mês de ocorrência do evento, 2002 . 
Tabela 4.6: Distribuição dos 170 formulários válidos coletados segundo o preenchimento de algumas de suas variáveis

Tabela 4.7: Distribuição de variáveis da DN Simplificada por faixas percentuais de não preenchimento.

Tabela 4.8: Distribuição das DNs Padrão por mês ocorrência do nascimento no ano de 2002 .

Tabela 4.9: Distribuição das DNs Simplificadas por mês ocorrência do nascimento no ano de 2002.

Tabela 4.10: Distribuição das DNs Reunidas por lote antes da eliminação de duplicidades. 49

Tabela 4.11: Distribuição das DNs Reunidas por lote depois da eliminação de duplicidades.

Tabela 4.12: Distribuição das DNs padrão e simplificada segundo preenchimento da variável Idade da Mãe.

Tabela 4.13: Distribuição das DNs padrão e simplificada segundo Idade da Mãe, excluidas as ignoradas

Tabela 4.14: Distribuição das DNs padrão e simplificada segundo preenchimento da variável Duração da Gestação 52

Tabela 4.15: Distribuição das DNs padrão e simplificada segundo Duração da Gestação. 
Tabela 4.16: Distribuição das DNs padrão e simplificadas por preenchimento de Consultas Pré-natal

Tabela 4.17: Distribuição das DNs padrão e simplificadas por ocorrência de consultas pré-natal.

Tabela 4.18: Distribuição das DNs padrão e simplificadas segundo número de consultas pré-natal.

Tabela 4.19: Distribuição das DNs padrão e simplificadas segundo preenchimento de número de filhos tidos vivos

Tabela 4.20: Distribuição das DNs padrão e simplificadas por preenchimento de número de filhos tidos mortos

Tabela 4.21: Distribuição das DNs padrão e simplificadas por número de filhos tidos vivos. 


\section{ÍNDICE}

1 Introdução

1.1 Inserção de um engenheiro na Saúde Pública …………............................... 1

1.2 Histórico anterior ao SINASC dos dados de nascidos vivos ..........................

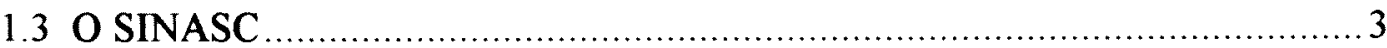

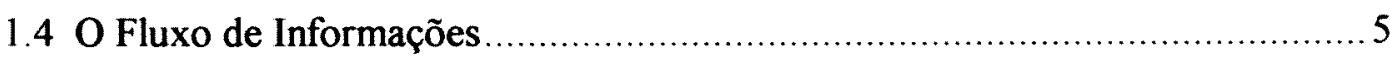

$1.5 \mathrm{Um}$ novo passo

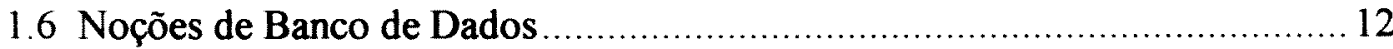

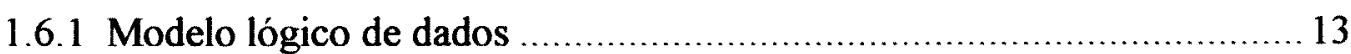

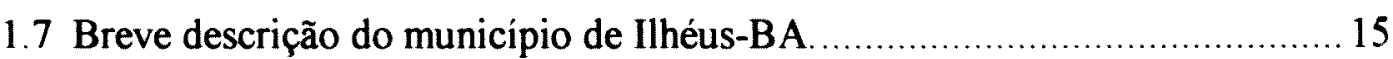

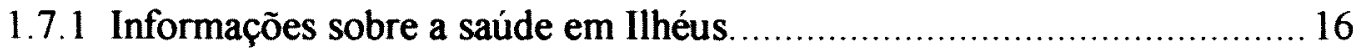

1.7.2 A escolha do município de Ilhéus ................................................. 17

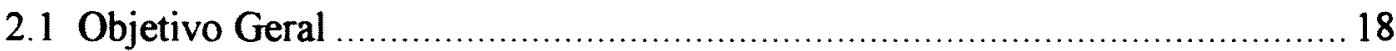

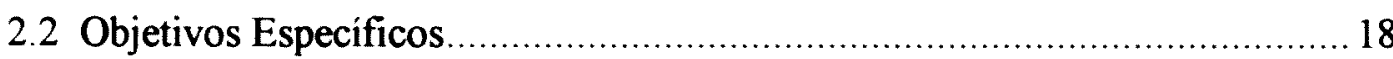

3 Métodos

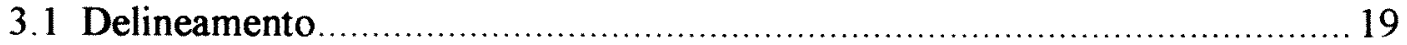

3.2 População de Estudo e Período de Referência ............................................. 19

3.3 Instrumento de Coleta de Dados - a DN Simplificada ……………...............20

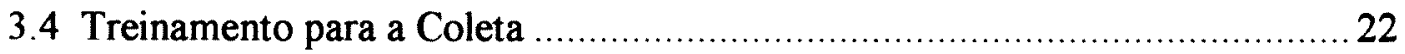

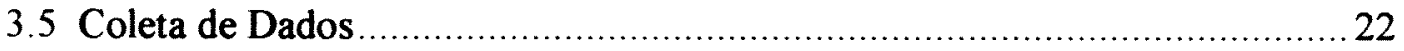

3.6 Criação do programa "SINASC - Interface Simplificada" ...........................23

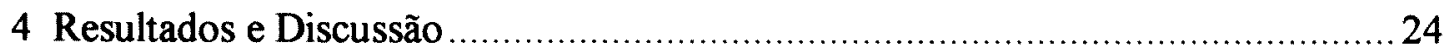

4.1 Aspectos da situação da coleta de dados em Ilhéus ……………..................24 
4.20 desenvolvimento do "SINASC - Interface Simplificada" ...................... 25

4.3 O programa de computador "SINASC - Interface Simplificada" ................ 26

4.3.1 As tabelas criadas para o "SINASC - Interface Simplificada" .............227

4.3.2 A manipulação do Banco de Dados ............................................... 32

4.3.3 A transferência dos dados para o SINASC Padrão .............................. 37

4.3.4 As rotinas de teste de DNs em duplicidade ............................... 40

4.4 Avaliação dos dados obtidos e das variáveis utilizadas ........................... 42

4.4.1 Os dados coletados pelo formulário simplificado.......................... 43

4.4.2 Análise do preenchimento do formulário simplificado...................... 44

4.4.3 Os dados coletados pelo SINASC Padrão ....................................... 47

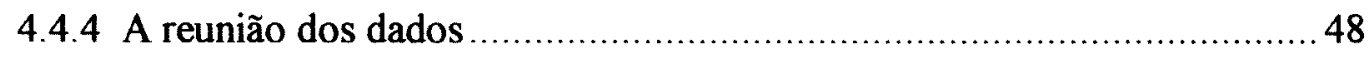

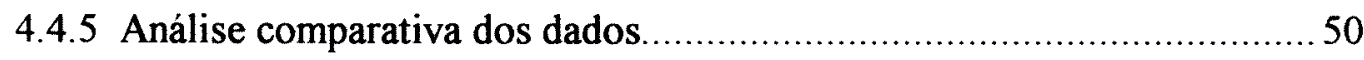

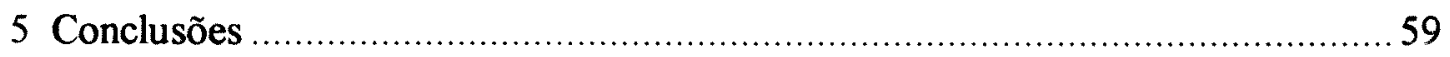

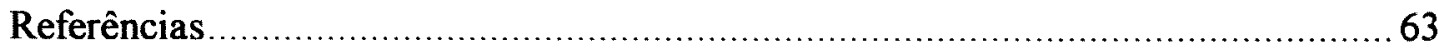

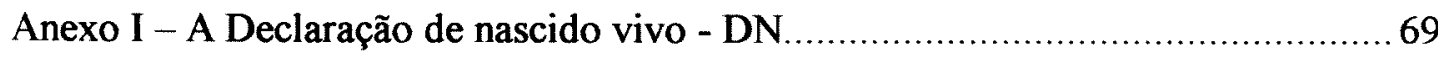

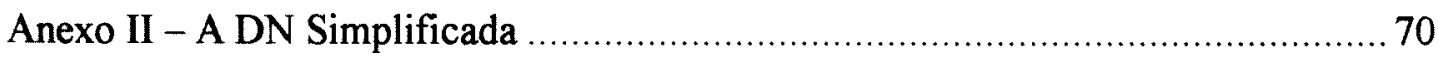

Anexo III - O manual de preenchimento da DN Simplificada ........................... 71

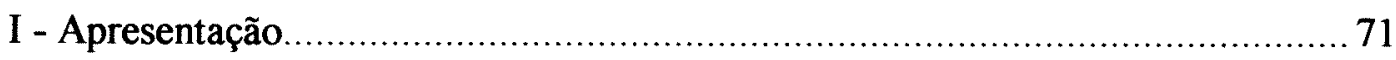

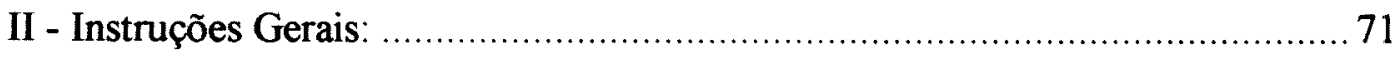

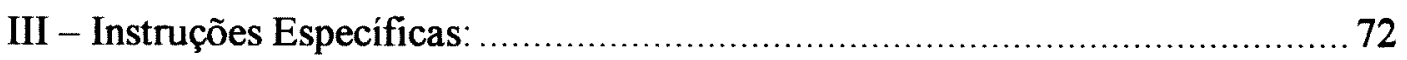




\section{INTRODUÇÃO}

\subsection{Inserção de um engenheiro na Saúde Pública}

A inserção do autor, formado em engenharia eletrônica, na Saúde Pública tem origem básica na própria inserção da informática em todas as áreas do conhecimento humano. A criação de uma disciplina de "Informática em Saúde" nos cursos de graduação do Departamento de Saúde da UEFS (Universidade Estadual de Feira de Santana - BA) gerou a contratação, por concurso público para professor, de engenheiros eletrônicos e analistas de sistema e a criação de um Laboratório de Informática em Saúde (LIS). Este primeiro contato com as necessidades e características do uso da informática na saúde gerou interesse crescente no grupo de professores do LIS, interesse que levou a contratos com a Secretaria da Saúde do Estado da Bahia (SESAB), sendo o primeiro em meados de 1998, para a realização do treinamento de pessoas de cada município do estado na implantação e uso de alguns dos sistemas de informação em saúde, a exemplo do SINASC (Sistema de Informação de Nascidos Vivos). O contato com os sistemas através de uma visão de programador e de instrutor no que diz respeito ao seu uso, gerou um grande interesse no grupo e no autor em contribuir de alguma forma para a melhoria deles. Resumidamente, estes são os eventos que levaram dois engenheiros a cursarem um Doutorado em Saúde Pública e um analista de sistemas a cursar um Mestrado em Saúde Coletiva. 


\subsection{Histórico anterior ao SINASC dos dados de nascidos vivos}

O conhecimento do número de nascidos vivos ocorridos em um determinado periodo, bem como de outras informações relacionadas aos nascimentos, é de fundamental importância para a elaboração de indicadores demográficos e de saúde (MELLO JORGE 1990). Antes da elaboração e implantação no Brasil do Sistema de Informação sobre Nascidos Vivos (SINASC), o Registro Civil era a única fonte nacional de obtenção desses dados, registro este estabelecido legalmente na Lei dos Registros Públicos (BRASIL 1973; BRASIL 1975). Nesta consta que todo nascimento que ocorrer no território nacional deve ser registrado no prazo de 15 dias (prazo dado ao pai), tempo que se amplia para 60 dias quando a mãe ou qualquer outro declarante for o responsável pela efetivação do registro.

Porém, a omissão deste registro é uma realidade presente no Brasil há bastante tempo, gerando o que é chamado de sub-registro (MELLO JORGE e col. 1997). Muitos são os trabalhos realizados que tentaram medir tal sub-registro (SAADE 1947; SCORZELLI JR. 1947; MORAES 1949; ROSADO 1949; PORTELA 1989; SOUZA e GOTLIEB 1993), resultando em se comprovarem valores elevados de perda de informação, perda esta maior ainda em áreas menos desenvolvidas (ALMEIDA 2000). Portanto, tais dados podem não corresponder à realidade. Problemas com a cobertura dos eventos (quantitativos), bem como com a correspondência da informação à realidade (qualitativos) (LAURENTI e col. 1985), levaram a uma busca por outras formas de obtenção de informação. Experiências internacionais e nacionais apontaram para os registros hospitalares como sendo uma fonte importante para complementar as deficiências de um sistema de coleta baseado apenas em registros civis. 


\subsection{O SINASC}

Em 1989 o Ministério da Saúde criou um grupo de trabalho sobre estatísticas vitais (MELLO JORGE 1990). Este grupo, com base em experiências de outros países e também do próprio Ministério da Saúde (a exemplo do SIM - Sistema de Informação de Mortalidade), decidiu implantar um sistema de informações sobre nascidos vivos. Implantado oficialmente em 1990 (MELLO JORGE e col. 1992), o Sistema de Informação sobre Nascidos Vivos (SINASC) tem por base um documento de padrão nacional, gerado nos hospitais e em outras instituições de saúde onde se realizam partos (para os partos hospitalares) e nos Cartórios de Registro Civil (para os partos ocorridos em domicílio). Seu formulário de entrada de dados padrão, a Declaração de Nascido Vivo - DN, cuja emissão também é de competência exclusiva do Ministério da Saúde (BRASIL 1997b), deve ser preenchida para todos os nascidos vivos no pais, segundo o conceito definido pela OMS de que nascido vivo é todo produto da concepção que, independentemente do tempo de gestação, depois de expulso ou extraido do corpo da mãe, respire ou apresente outro sinal de vida, tal como batimento cardiaco, pulsação do cordão umbilical ou movimentos efetivos dos músculos de contração voluntária, estando ou não desprendida a placenta.

Sua implantação foi acontecendo de forma gradual no pais, em paralelo à descentralização/municipalização' ${ }^{1}$ do sistema de saúde (SANTA HELENA e col. 1998; REPULLO 2001; ORTIZ 2002), sendo que, em alguns estados, ela não está completamente efetivada. Apesar disso, vem apresentando em muitos municípios,

\footnotetext{
${ }^{1}$ As regulamentação do processo de descentralização/municipalização do sistema de saúde estabelece que so receberão repasse de verbas federais os municípios que mantiverem regularidade na remessa de informações coletadas localmente pelos sistemas de informação de saúde, incluindo o SINASC (NOB-SUS 01/93, NOAS-SUS 01/2001).
} 
desde o ano de 1994, um volume maior de registros do que o publicado em anuários do IBGE com base nos dados de Cartórios de Registro Civil, e possibilita a construção de indicadores úteis para o planejamento e gestão dos serviços de saúde. Além da maior cobertura, o SINASC trouxe padronização, registro individualizado e a obtenção de maior número de informações do que o uso anterior do registro civil (ALMEIDA 2000), que se baseava em informação verbal registrada em livro e em mapa mensal.

Apesar das dificuldades institucionais do processo de implantação dos sistemas de informação em saúde e da alternância de governo municipal, estadual e das estratégias federais, que podem gerar alguma descontinuidade do Sistema, pode-se constatar a importância deste Sistema na elaboração de ações de vigilância e políticas de saúde (SANTA HELENA e WISBECK 1998). Diversos estudos apresentam as características dos nascidos vivos em cidades brasileiras, bem como avaliam o processo de implantação e o potencial de uso do sistema enquanto fonte de informação para o diagnóstico e planejamento de saúde (MELLO JORGE e col. 1992; MELLO JORGE e col. 1993; MELLO JORGE e col. 1997; RODRIGUES e col. 1997; MAIA 1997). Alguns autores apresentam a possibilidade de estabelecimento de ligação entre este sistema e outros do Ministério da Saúde (a exemplo do SIM - Sistema de Informação de Mortalidade), bem como outros sistemas desenvolvidos em nível local, voltados para a identificação de riscos e ações de prevenção (ALMEIDA e MELLO JORGE 1996; OLIVEIRA e PEREIRA 1997; NORONHA e col. 1997). 


\subsection{O Fluxo de Informações}

Os formulários de Declaração de Nascidos Vivos (Anexo I) são pré-numerados, impressos em três vias e distribuídos às Secretarias Estaduais de Saúde pela FUNASA/MS (Fundação Nacional de Saúde / Ministério da Saúde). As Secretarias Estaduais de Saúde se encarregavam, até bem recentemente, da sua distribuição aos estabelecimentos de saúde e cartórios. Embora isso não tenha ainda acontecido em todo o território nacional, o preconizado é que as Secretarias Municipais de Saúde assumam esse encargo.

No caso de gravidez múltipla, deve ser preenchida uma Declaração de Nascido Vivo (DN) para cada nascido vivo. O fluxo desses documentos (Figura 1.1) também apresenta uma variação de estado para estado, sendo recomendado pelo Ministério da Saúde (Portaria MS/FUNASA $n^{\circ} 475 / 2000$ ) que as $1^{\mathrm{a}}$ e $2^{\mathrm{a}}$ vias sejam recolhidas ativamente pelas Secretarias Municipais de Saúde para processamento, sendo a $1^{\text {a }}$ via recolhida nas unidades de saúde, para partos institucionais, e a $2^{\mathbf{a}}$ via recolhida nos cartórios, para nascimentos registrados de ambas as origens.

No caso de parto institucional, a unidade de saúde emite as três vias, retendo a $3^{\mathrm{a}}$ via em seus arquivos. A $2^{\mathrm{a}}$ via, é cedida à família para sua apresentação ao cartório por ocasião do registro do recém nascido. A $1^{\text {a }}$ via é separada para futura coleta da Secretaria Municipal de Saúde. Se o parto for domiciliar, uma DN será preenchida no próprio cartório (somente a $2^{\mathrm{a}}$ via) no momento em que a criança for registrada. $\mathrm{O}$ recolhimento destes formulários em suas fontes de preenchimento (hospitais e cartórios) é responsabilidade da Secretaria Municipal de Saúde, a ser feito 
regularmente e com intervalo de tempo o menor possível para possibilitar a pronta recuperação de informações por mau preenchimento dos campos da DN.

Figura 1.1 - Fluxo das vias das Declarações de Nascidos Vivos - DNs

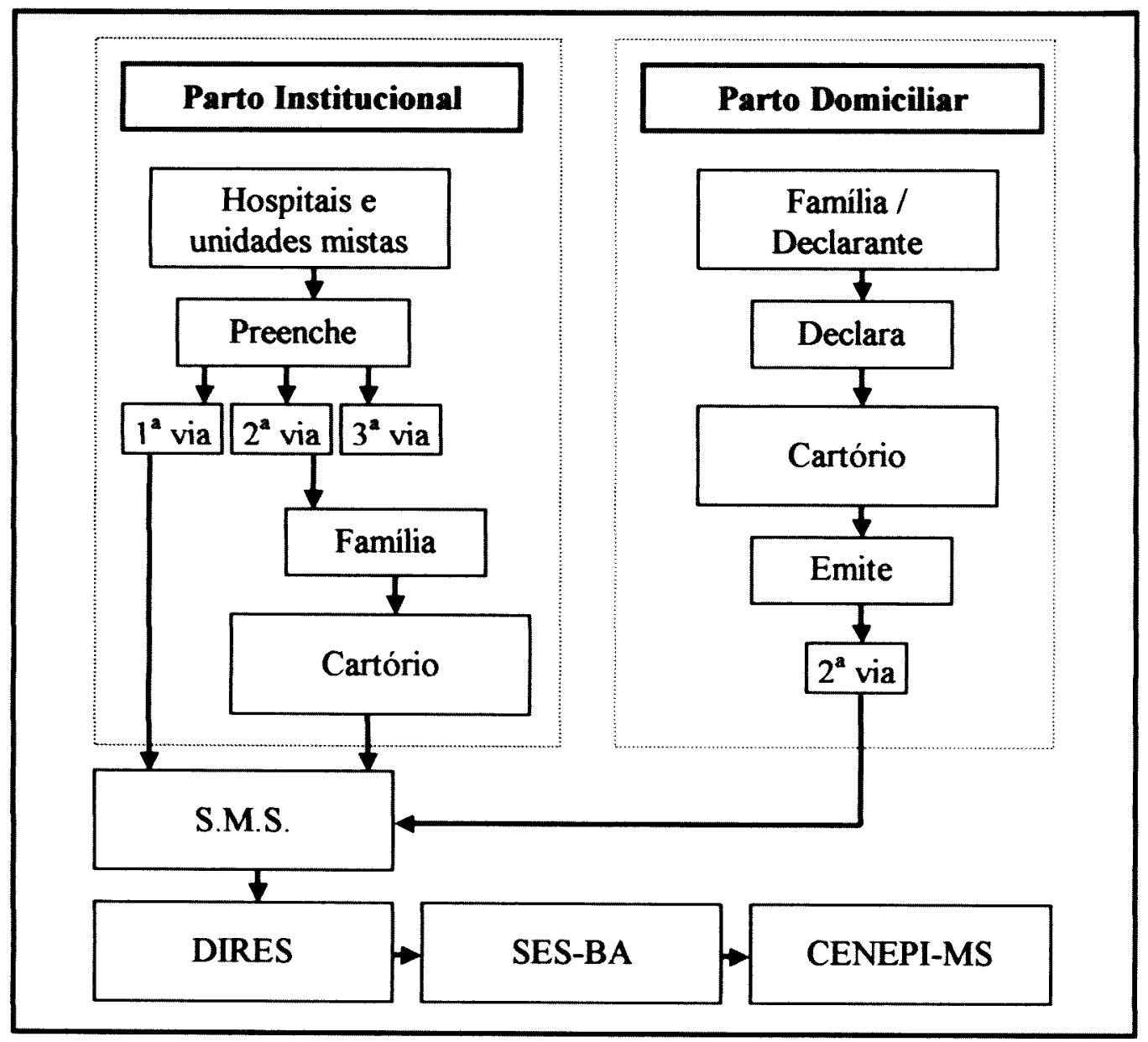

As primeiras vias recolhidas nas unidades de saúde são em geral recolhidas primeiro do que as segundas vias correspondentes (cartórios), pois o registro ocorre, quando ocorre, pouco ou bem depois de sua emissão pelo hospital. No momento da digitação, estas vias se complementam, cobrindo tanto nascimentos registrados em unidades de saúde que não foram efetivamente registrados em cartório, quanto partos apenas registrados em cartório (partos domiciliares). No caso da captação de ambas 
as vias, o sistema acusa o evento, dando ao digitador a opção de complementar as informações que uma via possa ter em relação à outra² .

Após o recolhimento das vias, mas antes de sua digitação, cada SMS deve fazer uma leitura crítica dos dados, testando assim a consistência e o real preenchimento destes para reenviá-los ao local que os emitiu em busca de correção ou confirmação de informações. Além disso, o próprio sistema (SINASC) tem críticas automáticas que geram relatórios para alertar o digitador sobre possiveis erros de digitação de dados, ou mesmo de preenchimento da declaração de nascido vivo, que não foram detectados na fase descrita anteriormente. Alguns pontos que exemplificam isto são: mãe de idade muito elevada; peso da criança muito alto em uma gravidez múltipla; peso da criança muito alto em um parto prematuro.

Nas Diretorias Regionais de Saúde (DIRES) os dados recebidos dos municípios sobre sua responsabilidade são agregados e uma segunda análise de consistência deve ser realizada, para então serem enviados para as Secretarias Estaduais de Saúde (SES)

Nas SES os dados devem sofrer uma terceira análise de consistência e uma redistribuição por DIRES e por município de residência do recém nascido, sendo este o dado que mais interessa aos profissionais do setor saúde. Das SES esses dados são enviados para o Ministério da Saúde, que procede a quarta análise de consistência e os reagrupa por estados de residência. Esses dados não estão restritos aos órgãos

\footnotetext{
${ }^{2}$ Se a primeira via for digitada primeiro, situação mais comum conforme comentários anteriores, a segunda via deve ser utilizada para complementar as informações referentes aos dados inseridos pelo cartório (ANEXO I). Porém, se a segunda via for digitada primeiro, a primeira via poderá ser descartada por não possuir nenhuma informação a mais que aquela.
} 
gestores (Ministério da Saúde, Secretarias Estaduais de Saúde e Secretarias Municipais de Saúde), sendo disseminados através de anuários estatísticos, da Internet e discos de leitura óptica (CD-ROM).

Gestores das três esferas de governo passaram a utilizar tais dados, ainda que de forma incipiente e, na maioria das vezes, como denominador para o cálculo de taxas, como as de mortalidade infantil e mortalidade materna, por exemplo. Apesar disso, alguns indicadores vêm sendo propostos, sendo a grande maioria voltada à avaliação da presença de fatores de risco do recém nascido e da rede de atenção à gravidez e ao parto. Entre os indicadores propostos encontram-se: proporção de nascidos vivos de baixo peso, proporção de prematuros, proporção de partos hospitalares cesáreos, proporção de nascidos vivos por faixa etária da mãe.

Outros indicadores para a avaliação da rede de serviços de atenção à gravidez e ao parto podem ser utilizados, como, por exemplo, a proporção de nascidos vivos com Apgar menor que 7 ( $1^{\circ}$ minuto); a proporção de nascidos vivos com mais de $2.500 \mathrm{~g}$, ou o número de consultas pré-natal, entre outros. Além desses, podem ainda ser calculados indicadores clássicos, voltados à caracterização geral de uma população, como a taxa bruta de natalidade e a taxa de fecundidade total.

\section{$1.5 \mathrm{Um}$ novo passo}

A padronização proporcionada pela implantação do SINASC representa um avanço para a obtenção de dados que permitem compatibilidade entre municípios, unidades federativas e paises. Analisando a cobertura de eventos pouco antes de e desde sua 
implantação, o SINASC contribui para um desempenho crescente na obtenção de informações de nascidos vivos (MELLO JORGE 1983; SOUZA 1992; PORTO ALEGRE 1995; MELLO JORGE 1996; KALE 1997; MAIA 1997; OLIVEIRA 1997; SANTA HELENA e col. 1998; DATASUS 2003), sendo em várias cidades brasileiras superior às estimativas do IBGE.

O processo de municipalização dos serviços de saúde, bem como a padronização de uma coleta de dados referentes a estes serviços, encontrou muitos municípios em que não havia nada parecido antes. Mas alguns municípios já possuíam alguma forma local de coleta de informações visando a gerência local dos serviços. Com a padronização, estes programas locais tiveram de dar lugar ao padrão, fato incentivado pelo vínculo obrigatório do fornecimento de informações coletadas no formato nacional com o recebimento de verbas para a área de saúde do município. Variáveis que localmente eram consideradas importantes, ou mesmo que possuiam um nível de detalhe maior, foram perdidas.

Municipios que possuem recursos hospitalares mais complexos, capitais e grandes cidades, poderiam se beneficiar de informações sobre seus nascidos vivos que não constam no documento padrão do SINASC. O modelo americano do sistema de informação de nascidos vivos leva em conta estas necessidades locais. Apesar de instituir um modelo nacional, este é definido como "conjunto mínimo de dados a serem coletados", e deixa a critério de estados e do nível local o uso de mais variáveis de coleta. Na revisão da DN americana ocorrida em 1989, o uso de certas variáveis extras foi até mesmo incentivado àqueles que tivessem condição de fazê-lo (UNITED STATES OF AMERICA 1991). 
O uso de um Sistema de informações de Nascidos Vivos com mais variáveis que o padrão, que poderia ser chamado de "SINASC - Interface Avançada", poderia também servir ao propósito de suprir de informações a Sistemas Sentinelas (WALDMAN 1998, BRASIL 2001) que atuam na vigilância em saúde pública. Por exemplo, um município que possui um número elevado de unidades de saúde que realizam partos poderia escolher um deles para servir de Hospital Sentinela, instalando neste o "SINASC - Interface Avançada". Os eventos deste hospital serviriam de alerta para a avaliação da atenção ao parto (BRASIL 2001).

Uma outra necessidade do SINASC diz respeito à sua cobertura dos partos domiciliares. Uma comparação realizada entre a Pesquisa Nacional em Demografia e Saúde (PNDS) de 1996 (BRASIL 1997a) e os dados equivalentes coletados pelo SINASC (ALMEIDA 2000) aponta deficiências de captação do SINASC de partos domiciliares, principalmente nos estados das regiões norte e nordeste. Esse problema ocorre tanto devido a sub-registro como a sub-notificação (também chamada de subcoleta) (OLIVEIRA e PEREIRA 1997).

De acordo com os documentos legais que regem os Registros Públicos (BRASIL 1973; BRASIL 1975), todos os nascimentos e óbitos devem ser registrados nos Cartórios do Registro Civil, sendo o não cumprimento disto chamado sub-registro. Além disso, nascimentos registrados em cartório e não informados ao SINASC geram sub-notificação. O Relatório final do grupo de trabalho reunido em GoiâniaGO em 1997 (ORGANIZAÇÃO PAN-AMERICANA DE SAÚDE 1997.) menciona que a sub-notificação nos dados observados foi de cerca de $11 \%$ dos registrados em cartório. 
Alguns estudos mostram que a subenumeração dos dados do SINASC poderia ser diminuída por algum mecanismo de complementação com os dados para o Sistema de Informação de Atenção Básica (SIAB/MS) (MELLO JORGE 2001). Porém, agentes comunitários do Programa de Saúde da Família (PSF) coletam, diretamente nos domicílios, os dados do SIAB através do formulário chamado "Ficha B-GES" (SIAB 1998) que registram várias gestantes em cada um, senda estas identificadas individualmente, e depois totalizadas em formulários chamados "Relatório SSA2" e "Relatório SSA4", dificultando o seu aproveitamento.

A existência de um modelo simplificado, individualizado, para coleta de informação dos partos domiciliares beneficiaria todo e qualquer município, mas principalmente os municípios menores, pois nestes o seu número pode ser ainda mais representativo. Um formulário contendo dados básicos, que podem ser coletados mesmo dias depois da ocorrência do nascimento, aumentaria a cobertura do sistema. Agentes comunitários do Programa de Saúde da Família (PSF) poderiam realizar a coleta dos partos domiciliares que não são registrados em cartório e que, portanto, estão de fora do alcance do atual SINASC. Os dados assim coletados alimentariam um programa de computador especialmente criado para isso, uma nova interface para o SINASC, que poderia ser chamado de "SINASC - Interface Simplificada", possuindo um banco de dados próprio, mas com mecanismos de transferência para o SINASC padrão.

O desenvolvimento de ambas as interfaces aqui sugeridas, resultando nos programas "SINASC - Interface Simplificada" e "SINASC - Interface Avançada", baseados em sistemas de banco de dados distintos que converteriam seu conteúdo para o sistema 
padrão utilizado pelo SINASC, solucionariam ou amenizariam as deficiências apontadas. Por fim, a incorporação de tais interfaces ao próprio SINASC, o que é plenamente possível de ser realizado com a tecnologia existente, resultaria em um SISTEMA DE INFORMAÇÃO DE NACIDOS VIVOS DE MÚLTIPLA INTERFACE, para o que este trabalho se propõe a ser um primeiro passo, na medida em que se dispõe a criar tão somente o "SINASC - Interface Simplificada".

\subsection{Noções de Banco de Dados}

A importância da reunião e análise de grandes quantidades de informação para a tomada de decisões nas diversas organizações propiciou o desenvolvimento dos sistemas de processamento de informações. Sistemas de Gerenciamento de Bancos de Dados (SGBDs) permitem o armazenamento de grandes volumes de dados, estruturados em registros e tabelas, com recursos para acesso e processamento das informações (DATE 1991).

Um Banco de Dados (BD) é uma coleção de dados inter-relacionados, representando informações sobre um domínio específico (KORTH 1994), enquanto um SGBD é um software com recursos específicos para facilitar a manipulação das informações dos bancos de dados e o desenvolvimento de programas aplicativos, provendo a interface entre os dados de baixo nível armazenados num banco de dados e os usuários e aplicações que desejam acessá-los e/ou manipulá-los (RAMAKRISHNAN 1998). Por fim, um Sistema de Bancos de Dados (SBD) é um sistema de manutenção de registros por computador, envolvendo quatro componentes principais: os dados, o hardware, o software e os usuários. 
O SBD pode ser considerado como uma sala eletrônica de arquivos (Date 1991) que possui uma série de métodos, técnicas e ferramentas visando sistematizar o seu desenvolvimento. Os componentes de um SBD são: SGBDs, softwares, BDs, usuários. A criação de um SBD tem por objetivo isolar os usuários dos detalhes mais internos dos bancos de dados e prover independência aos aplicativos que farão uso de tais BDs, definindo estruturas físicas de armazenamento e estratégias de acesso. Assim, obtem-se rapidez na manipulação e no acesso à informação, disponibilização da informação no tempo necessário, controle integrado de informações distribuídas fisicamente, compartilhamento de dados, redução de redundância e de inconsistência de informações, redução de problemas de integridade, aplicação automática de restrições de segurança, e tudo isso com redução do esforço humano tanto no desenvolvimento (programador) como na utilização (gerenciador, usuário) (ELMASRI 1994).

\subsubsection{Modelo lógico de dados}

Existem alguns tipos de modelos lógicos de dados. Como neste trabalho só são analisados bancos de dados estruturados em registros, este tópico abordará apenas conceitos básicos de modelos lógicos baseados em registros. Quando um BD está estruturado segundo tais modelos, ele está dividido em tabelas (podendo possuir apenas uma), cujas colunas definem os campos e cujas linhas armazenam os registros (HEUSER 1998).

Cada campo de uma tabela possui as seguintes características: nome, tipo e formato

(Date 1991). Por exemplo, em uma tabela que armazena dados sobre nascidos vivos, 
o nome da mãe do recém-nascido pode ser guardado no campo descrito da seguinte maneira:

- Informação contida no campo: nome da mãe;

- Nome do campo: nomemae;

- Tipo: string;

- Formato: 40 caracteres.

A informação do "nome da mãe" do recém-nascido será guardada no campo "nomemae", sendo do tipo "string" (significando que podem ser armazenados nela quaisquer caracteres alfanuméricos) e seu formato é de 40 caracteres (significando que ela comporta de zero a quarenta caracteres alfanuméricos). Outros tipos e formatos de campos relevantes para este projeto podem ser vistos na Tabela 1.1, um exemplo de definição de tabela pode ser observado na Tabela 1.2 , e a Tabela 1.3 contém uma tabela criada segundo tal definição.

O conjunto de campos de um banco de dados define assim as colunas de uma tabela cujas linhas são preenchidas com os dados referentes a cada nascido vivo. Cada linha assim criada é chamada de registro. Uma tabela tem, portanto, seu número de campos (colunas) fixo, podendo possuir uma quantidade qualquer de registros (linhas), cada um criado para computar dados sobre um único evento.

Por se organizar os dados a serem manipulados em tabelas de um BD, a manipulação da informação se torna mais fácil, rápida e confiável, podendo-se consultar, inserir, editar ou excluir dados armazenados conforme a necessidade 
Tabela 1.1: Tipos e Formatos de campos

\begin{tabular}{l|l}
\hline Tipos & \multicolumn{1}{c}{ Descrição de possiveis Formatos } \\
\hline String & armazena o máximo de “n” caracteres, sendo n inteiro maior que zero \\
Data & armazena datas em diversos formatos: 10/07/02, 10/07/2002, 10-jul-02 \\
Hora & armazena horas em diversos formatos: 10:15pm, 22:15, 22:15:37,45 \\
Lógica & armazena um estado lógico 0 ou 1, falso ou verdadeiro \\
Inteiro & armazena um valor numérico inteiro cujo valor máximo é especificado \\
Real & armazena um valor real, ou seja, com possibilidade de casas decimais \\
\hline
\end{tabular}

Tabela 1.2: Exemplo de definição dos Tipos e Formatos de campos de uma tabela

\begin{tabular}{l|ccc}
\hline Informação contida no campo & Nome & Tipo & Formato/Tamanho \\
\hline Nome da mãe & nomemae & string & 40 caracteres \\
Data de nascimento da mãe & dtnascmae & data & $\mathrm{dd} / \mathrm{mm} /$ aaaa \\
Sem nascidos vivos anteriores & semnascviv & lógica & sim ou não \\
Número de consultas pré-natal & consultas & inteiro & numérico de 0 a 255 \\
\hline
\end{tabular}

Tabela 1.3: Exemplo de Tabela de um Banco de Dados especificada pela Tabela 1.2.

\begin{tabular}{l|ccc}
\hline nomemae & dtnascmae & semnascviv & consultas \\
\hline Maria Antônia Souza & $10 / 01 / 1972$ & não & 3 \\
Andréa Araújo de S. Fonseca & $12 / 04 / 1969$ & não & 0 \\
Marta Silva Santos & $31 / 12 / 1978$ & não & 5 \\
Joana Cerqueira Fontes & $03 / 01 / 1981$ & sim & 2 \\
\hline
\end{tabular}

\subsection{Breve descrição do município de Ilhéus-BA.}

Situado na região sul da Bahia, denominada Micro-Região Cacaueira, o município de Ilhéus ocupa uma área total de $1.712 \mathrm{~km} 2$ e apresenta no seu relevo dois aspectos distintos: uma área de elevação e outra de planície litorânea. Possui extensa zona rural, com cerca de 35 localidades, das quais 11 são sedes distritais. A maioria 
margeia o litoral ou os rios que banham o municipio (Cachoeira e Almada). A distância entre o município de Ilhéus e a capital do estado, Salvador, é de $465 \mathrm{~km}$, sendo sua temperatura média anual de $24,5^{\circ}$ e seu índice pluviométrico anual médio de $2000 \mathrm{~mm}$ (clima intertropical úmido) (SOUZA 2000). Sua população é de pouco mais de 250.000 habitantes, sendo atualmente o terceiro município de maior população do estado da Bahia, distribuídos na zona urbana e rural na proporção de cerca de $71 \%$ e $29 \%$ respectivamente (ILHÉUS 1998 ).

\subsubsection{Informações sobre a saúde em Ilhéus.}

As informações a seguir apontam para uma crescente atividade da Secretaria de Saúde Municipal em prol da melhoria da saúde em Ilhéus. A cobertura do Programa de Agentes Comunitários de Saúde (PACS) do município de Ilhéus em 1996 era de aproximadamente $27 \%$, sendo em 1999 de $50 \%$ e em 2000 de $60 \%$. No que se refere ao percentual de gestantes acompanhadas pelos agentes comunitários de saúde foi de 100\% em 1997 e de 95,4\% em 1998. Quanto à realização de consultas pré-natais, em 1997 e 1998 estiveram em dia $54,1 \%$ e $65,97 \%$ das gestantes respectivamente, sendo que $25,18 \%$ em 1997 e $38,79 \%$ em 1998 iniciaram as consultas no $1^{\circ}$ trimestre (SOUZA 2000).

Há no município de Ilhéus 80 estabelecimentos de saúde de diversos níveis de complexidade (ver Tabela 1.4). A rede básica municipal (atenção primária e secundária) é constituída por 22 postos de saúde, 6 centros de saúde, 4 núcleos de saúde da família e 3 unidades móveis médico-odontológicas. 
Tabela 1.4: Distribuição do número de estabelecimentos de saúde existentes no município de Ilhéus, 1999.

\begin{tabular}{lccc}
\hline Tipo de Estabelecimento & Credenciados SUS & Não credenciados SUS & Total \\
\hline Hospital & 5 & 1 & 6 \\
Clinica & 8 & 19 & 27 \\
Consultório & 3 & - & 3 \\
Centro de Saúde & 6 & - & 6 \\
Posto de Saúde & 22 & - & 22 \\
Núcleo de Saúde & 3 & - & 3 \\
Laboratório & 5 & 6 & 11 \\
Ambulatório/Sindicato & 2 & - & 2 \\
\hline Total & 54 & $\mathbf{2 6}$ & $\mathbf{8 0}$ \\
\hline
\end{tabular}

Fonte: Secretaria de Saúde - Município de Ilhéus-BA.

Atualmente, o Programa de Atenção Integral à Saúde da Mulher (PAISM) encontrase em funcionamento em 5 unidades de saúde e tem por objetivo atender às necessidades globais da saúde feminina. Ele incorpora além da assistência ao prénatal, parto e puerpério, a resposta organizada dos serviços de saúde à contracepção, esterilidade, deteç̧ão precoce do câncer ginecológico, DST's, sexualidade, adolescência e climatério, considerando as dimensões psicológicas e sociais nessa atenção e a promoção de práticas educativas.

\subsubsection{A escolha do município de Ilhéus}

O municipio de Ilhéus foi escolhido para a realização desta pesquisa por ser um excelente local para a aplicação de um novo formulário simplificado de coleta de dados sobre nascidos vivos, pois possui uma população significativa (terceiro município mais populoso da Bahia) e um grande e crescente efetivo de agentes do PACS nos últimos anos, dos quais se pode constatar excelente disposição de efetuar a aplicação dos formulários desta pesquisa nos domicílios por eles visitados. 


\section{OBJETIVOS}

\subsection{Objetivo Geral}

Desenvolver e testar um programa de computador chamado "SINASC - Interface Simplificada" para servir de interface complementar ao SINASC visando o aprimoramento da captação e da utilização de suas informações através de DNs simplificadas a serem coletadas pelos agentes do "Programa de Agentes Comunitários de Saúde (PACS) / Programa de Saúde da Família (PSF)".

\subsection{Objetivos Específicos}

Avaliar a introdução de um modelo de DN simplificada de modo a padronizar a coleta de dados individualizada de nascidos vivos pelos agentes comunitários do PACS.

Possibilitar o aumento da cobertura do SINASC no que se refere a partos domiciliares por facilitar a coleta das informações diretamente nos domicílios (partos não registrados em cartório) e/ou utilizar informações do PACS como forma complementar ao SINASC. 


\section{MÉTODOS}

\subsection{Delineamento}

Trata-se de um estudo exploratório e do desenvolvimento de um modelo padronizado, a DN Simplificada (Anexo II), para a coleta de dados individuais de nascidos vivos no domicilio, bem como do teste de um programa de computador complementar ao SINASC padrão chamado "SINASC - Interface Simplificada".

\subsection{População de Estudo e Período de Referência}

Foram obtidos dados sobre os nascidos vivos hospitalares e/ou domiciliares referentes ao periodo de 01/05/2002 a 31/07/2002 (três meses) coletados por agentes comunitários do PACS/PSF do município de Illhéus-Ba. Para a realização de uma análise comparativa, foram obtidos na Secretaria Municipal de Saúde de Ilhéus os dados do SINASC referentes ao mesmo periodo.

Como o SINASC é alimentado por unidades de saúde e por cartórios, existe um atraso entre o evento a ser registrado e a digitação deste evento no sistema de informações, sendo tal atraso maior para os chamados partos domiciliares captados apenas pelo registro em cartório. Assim, para minimizar perdas devidas a atrasos, os dados do SINASC serão complementados com informações colhidas até 30/09/2002, ou seja, dois meses após o último dia do período de coleta. Este prazo foi escolhido com base nas leis que regem o registro público (BRASIL 1973; BRASIL 1975), que estabelecem prazo de quinze dias para que o pai realize o registro do recém-nascido, 
sendo estendido por mais quarenta e cinco dias para que a mãe o faça na falta ou impedimento do pai.

\subsection{Instrumento de Coleta de Dados - a DN Simplificada}

No processo de coleta das informações sobre nascidos vivos em suas visitas aos domicílios, os agentes comunitários não estariam aptos a coletar certas informações por não terem treinamento profissional apropriado ou por que algumas só são coletáveis no momento do parto (a exemplo do índice de apgar e do peso ao nascer). Porém, há informações que podem ser obtidas por esses agentes que reverterão no conhecimento do número de eventos e em uma qualificação mínima destes. Para tais informações, na medida do possivel, foram mantidas as categorias das variáveis e os códigos de campos utilizados pela "Declaração de Nascido Vivo" padrão. Portanto, as variáveis a constarem no formulário da "Declaração de Nascido Vivo Simplificada" são (ver Anexo II):

- Dentro do módulo III (Mãe):

○ Nome da Mãe;

- Data de Nascimento: (dia/mês/ano);

○ Número de filhos vivos anteriores: marcador para nenhum;

- Número de filhos vivos anteriores: quantidade;

- Número de filhos mortos anteriores: marcador para nenhum;

- Número de filhos mortos anteriores: quantidade;

○ Residência (Logradouro, Número, Complemento, CEP, Bairro, Município, UF); 
- Dentro do módulo IV (Gestação e Parto)

- Data da última menstruação: (dia/mês/ano);

o Tipo de Gravidez: 1-Unica, 2-Dupla, 3-Tripla, 9-Ignorado;

- Número de consultas pré-natal;

- Dentro do módulo V (Recém Nascido):

- Data e Hora de Nascimento do Recém Nascido: (dia/mês/ano), (horas:minutos);

o Sexo: M-Masculino, F-Feminino, I-Ignorado;

- Dentro do módulo VI (Pai):

- Nome do Pai;

- Dentro do módulo VII (Preenchimento):

- Nome de quem preencheu;

o Data de preenchimento: (dia/mês/ano);

Algumas variáveis diferem em formato ou nível de detalhamento quando comparadas com as usadas na DN padrão, a saber:

- A informação sobre a data de nascimento, ao invés da idade da mãe, visa testar a possibilidade de se obter uma informação que segue as normas internacionais de identificação individual;

- No item "Número de filhos anteriores", além do campo para a quantidade, foi criado um campo "nenhum" para ser marcado no caso de nenhum filho anterior 
(tanto para vivos como para mortos). Isto objetivou identificar se o campo para a quantidade deixado em branco seria um ignorado ou a quantidade nula;

- A variável data da última menstruação visa obter a idade gestacional exata do recém-nascido ao invés da duração da gestação em intervalos pré-classificados de semanas, tal como se encontra na Declaração de Nascido Vivo padrão, e tem por objetivo testar se é possível obter esta informação das mães;

- O número de consultas pré-natal realizadas foi registrado ao invés de classificá-lo em intervalos tal como se encontra na Declaração de Nascido Vivo padrão;

- A reintrodução do nome do pai, pois alguns estudos mostram a importância desta variável.

\subsection{Treinamento para a Coleta}

Em reunião realizada no inicio de abril de 2002 com as coordenadoras do PACS/PSF de Ilhéus, foram apresentados os formulários e o manual de preenchimento destes (Anexos II e III), bem como foi apresentado em palestra um resumo do trabalho do projeto de pesquisa. Em seguida, realizou-se treinamento das coordenadoras, baseado no manual distribuído, as quais posteriormente treinaram os agentes comunitários.

\subsection{Coleta de Dados}

Cerca de oitenta agentes comunitários efetivamente participaram da coleta de cento e setenta e seis formulários, que ficou restrita à área de atuação do PACS/PSF. Visto 
que, destes, cinco se referiam a nascidos no mês de abril e um não continha o dado "data de nascimento", apenas cento e setenta foram considerados válidos.

\subsection{Criação do programa "SINASC - Interface Simplificada"}

Tendo por base o programa de computador SINASC, versão para Windows distribuida pelo DATASUS, foi elaborado o programa "SINASC - Interface Simplificada" para que nele fossem digitados os formulários coletados. Isto foi feito utilizando o programa "BORLAND C++ BUILDER 5", que se trata de um editor e compilador " $\mathrm{C}++$ " para o sistema operacional Windows

O banco de dados do programa "SINASC - Interface Simplificada" pode ser transferido para os moldes do banco de dados do SINASC padrão através de uma rotina de conversão criada para isso, tornando os dados recolhidos pelo novo programa compatíveis e prontos para se efetuar a exportação das informações do município para o nível central. Nesta conversão vários dados no formato padrão ficaram em branco, pois não foram coletadas todas as variáveis da Declaração de Nascido Vivo padrão.

Rotinas de teste de duplicidade de DNs para ambos os bancos também foram implementadas de modo a permitir a deteç̧ão de registros redundantes de nascidos vivos. 


\section{RESULTADOS E DISCUSSÃO}

\subsection{Aspectos da situação da coleta de dados em Ilhéus}

Este tópico tem por objetivo contribuir para o entendimento dos dados coletados. Em várias visitas à Secretaria de Saúde de Ilhéus, bem como a outras dependências vinculadas, foi constatada uma grande disposição em participar em qualquer processo que contribuísse de alguma forma para a melhoria da saúde no município. O apoio local da equipe do PACS/PSF a esta pesquisa foi surpreendente e bem além das expectativas iniciais, tornando a coleta um processo suave e sem maiores obstáculos. Porém, foram detectados problemas na rotina de coleta de dados do SINASC

Os problemas começam pelo preenchimento das declarações de nascidos vivos nas unidades de saúde. O responsável pela digitação dos formulários informou que há campos em branco com grande freqüência, a exemplo do sexo do recém-nascido. Falhas no preenchimento do nome da mãe também foram apontadas. Pior que isto é o fato de que as unidades de saúde, por vezes, atrasam a entrega dos formulários ao responsável pela coleta, atraso que varia de dois a cinco meses. A causa informada para tal atraso é a "perda" de formulários já preenchidos que são eventualmente reencontrados meses depois. Um exemplo extremo disso ocorreu em junho de 2001 quando um dos hospitais “achou e entregou” DNs preenchidas do ano de 1999.

Além disso, a coleta dos formulários junto às unidades de saúde não ocorre de forma 
sistemática, ficando a depender de disponibilidade do único carro que realiza este entre outros serviços. Já a coleta junto aos cartórios não ocorre, fato que pode ser visto na ausência de dados de cartório na totalidade das DNs do banco de dados dos primeiros sete meses do ano de 2002. Por fim, as DNs coletadas são agrupadas em lotes de 50 e enviadas mensalmente no dia 25 de cada mês.

\subsection{O desenvolvimento do "SINASC - Interface Simplificada"}

A idéia original de criação do "SINASC - Interface Simplificada" era de utilizar os arquivos-fonte do programa SINASC como base em cima da qual seriam criadas as rotinas necessárias para a captação e análise dos dados coletados no formato simplificado. Os arquivos-fonte (AHO e col. 1995) de um programa de computador são os arquivos criados diretamente pela ação do programador a partir dos quais um outro programa, chamado de compilador, gera o programa final, o "executável", pronto para ser usado em qualquer computador que tenha um sistema operacional compatível (SILBERSCHATZ e col. 1998). Cada compilador possui regras próprias que regem o formato e a linguagem dos arquivos-fonte. Algumas linguagens bem conhecidas são BASIC, PASCAL e C.

Como o órgão responsável pela criação e atualização do SINASC, o DATASUS, tem usado o DELPHI (um compilador PASCAL) nas suas últimas versões do seu programa, a criação do "SINASC - Interface Simplificada" teria de ser feita no mesmo compilador, pois somente este seria capaz de ler seus arquivos-fonte.

Infelizmente, os arquivos-fonte do SINASC não foram disponibilizados. Desta 
forma, ficou livre a escolha do compilador a ser usado na criação do novo programa, que recaiu sobre o "BORLAND C++ BUILDER 5" (um compilador $\mathrm{C}++$ ) (GUNNERSON 2001). Fatores que levaram a esta decisão foram tanto o poder da ferramenta como o fato de seu uso ser bem difundido. Estudos comparativos mostram que a linguagem $\mathrm{C}$ é mais poderosa do que a linguagem PASCAL (SPRINGER 1979, FEUER e col. 1979, MATETI 1979, FEUER e col. 1980). O poder de uma linguagem é conseqüência de suas características estruturais, que definem os meios disponíveis para se obter soluções para os mais diversos problemas com maior ou menor grau de complexidade de linhas de código digitadas nos arquivos-fonte. Da comparação destas duas linguagens, um resultado comum é a frase: C foi criado para realizar tarefas, enquanto PASCAL foi criado como ferramenta para o aprendizado em programação. Esta frase expressa uma realidade, ou seja, é uma descrição simplificada do real objetivo que os desenvolvedores de tais linguagens tiveram no ato de suas respectivas criações (KERNIGHAN 1981).

\subsection{O programa de computador "SINASC - Interface Simplificada"}

O "SINASC - Interface Simplificada", criado através da ferramenta "Borland C++ Builder" versão 5.0 , é um programa de computador que pode ser utilizado nos sistemas operacionais "Windows 95" e posteriores versões do Windows até a presente data. Segue uma descrição desse programa tanto pela sua funcionalidade (ponto de vista do usuário), bem como pela sua estrutura (ponto de vista do programador). Tal descrição se restringirá a pontos considerados relevantes para o entendimento do funcionamento do "SINASC - Interface Simplificada". 


\subsubsection{As tabelas criadas para o "SINASC - Interface Simplificada"}

O Banco de Dados do "SINASC - Interface Simplificada" possui apenas os seguintes quatro tipos de tabelas (descritas detalhadamente nas Tabelas 4.1, 4.2, 4.3 e 4.4), sendo que para cada ano de digitação de eventos implicará em uma tabela de cada um destes tipos:

- Tipo 1: Tabela anual de dados coletados pelo formulário "DN - Simplificada", que possui por registros cada nascimento coletado em um determinado ano. Esta tabela anual foi criada no formato Paradox, e possui por nome o ano e por extensão “.db”. Ex.: "2002.db”.

- Tipo 2: Tabela anual de dados no formato do SINASC Padrão, que possui por registros cada nascimento coletado em um determinado ano convertidos a partir da tabela tipo 1. Esta tabela anual foi copiada em suas especificações e formato do SINASC Padrão, possuindo, portanto, formato Dbase e nome composto assim: DN + "sigla do estado" + "ano" + a extensão “.dbf". Ex.: "DNBA2002.dbf".

- Tipo 3: Tabela anual de dados de controle no formato do SINASC Padrão, sendo que cada registro seu faz referência a um registro da tabela tipo 2 , identificando a que lote cada DN pertence. Esta tabela anual foi copiada em suas especificações e formato do SINASC Padrão, possuindo, portanto, formato Dbase e nome composto assim: $\mathrm{AD}+$ "sigla do estado" + "ano" + a extensão “.dbf”. Ex.: "ADBA2002.dbf". 
- Tipo 4: Tabela anual de dados de controle no formato do SINASC Padrão, sendo que cada registro seu faz referência a um lote de DNs da tabela tipo 2, identificando a quantidade de DNs em cada lote. Esta tabela anual foi copiada em suas especificações e formato do SINASC Padrão, possuindo, portanto, formato Dbase e nome composto assim: CT + "sigla do estado" + "ano" + a extensão “.dbf". Ex.: "CTBA2002.dbf".

Posteriormente, outras tabelas complementares (a exemplo da tabela de bairros) poderão ser criadas, aumentando a versatilidade e complexidade do sistema simplificado. Dentro da única tabela realmente criada por esta pesquisa foram criados vinte e cinco campos conforme descritos na Tabela 4.1.

Tabela 4.1: Descrição das características dos campos da tabela simplificada do Banco de Dados do "SINASC - Interface Simplificada". (2002.db) (um registro para cada DN - simplificada).

\begin{tabular}{l|ccc}
\hline Informação contida no campo & Nome & Tipo & Tamanho/formato \\
\hline Número do formulário da DN & numerodn & string & 8 caracteres \\
Nome da mãe & nomemae & string & 40 caracteres \\
Número SUS da mãe & numsusmae & string & 11 caracteres \\
Data de nasc. da mãe ignorada & semdatanascmae & lógica & sim ou não \\
Data de nascimento da mãe & datanascmae & data & dd/mm/aaaa \\
Nenhum nascido vivo & semfilvivo & lógica & sim ou não \\
Número de n. v. anteriores & qtdfilvivo & string & 2 caracteres \\
Nenhum nascido morto & semfilmort & lógica & sim ou não \\
Número de n. m. anteriores & qtdfilmort & string & 2 caracteres \\
Endereço de residência da mãe & endres & string & 50 caracteres \\
Número (residência) & numres & string & 6 caracteres \\
Complemento (residência) & complres & string & 20 caracteres \\
CEP (residência) & cepres & string & 8 caracteres \\
Bairro (residência) & baires & string & 30 caracteres \\
\hline
\end{tabular}




\begin{tabular}{l|ccc}
\hline Código do bairro (residência) & codbaires & string & 3 caracteres \\
Código do município (res.) & codmunres & string & 7 caracteres \\
Sem data última mestruação & semdataultimamenstr & lógica & sim ou não \\
Data da última mestruação & dataultimamenstr & data & dd/mm/aaaa \\
Tipo da gravidez & gravidez & string & 1 caractere \\
$\mathrm{N}^{\circ}$ de consultas pré-natal & qtdconsultas & string & 1 caractere \\
Sem data nascimento do r. $\mathrm{n}$. & semDdatanasc & lógica & sim ou não \\
Data de nascimento do r. $\mathrm{n}$. & Ddatanasc & data & $\mathrm{dd} / \mathrm{mm} / \mathbf{a a a a}$ \\
Sem hora nascimento do r. $\mathrm{n}$. & semHhoranasc & lógica & sim ou não \\
Hora de nascimento do r. $\mathrm{n}$. & Hhoranasc & hora & hh.mm \\
Sexo do r. n. (recém-nascido) & sexo & string & 1 caractere \\
Nome do pai & nomepai & string & 40 caracteres \\
Nome de quem preencheu & nomepreencheu & string & 40 caracteres \\
Sem data do preenchimento & semdatapreencheu & lógica & sim ou não \\
Data do preenchimento & datapreencheu & data & dd/mm/aaaa \\
Número do lote & numerolote & string & 4 caracteres \\
Status da DN - simplificada & status & inteiro & numérico \\
\hline
\end{tabular}

Conforme visto na definição dos tipos de tabelas. três tabelas do banco de dados do SINASC Padrão tiveram de ser examinadas e suas características analisadas para que o programa "SINASC - Interface Simplificada" pudesse gerar a conversão de seus dados e posterior transferência para o SINASC. Eis as caracteristicas de tais tabelas.

Tabela 4.2: Descrição das características dos campos da DNBA2002.DBF (um registro para cada $\mathrm{DN}$ ).

\begin{tabular}{l|ccc}
\hline Informação contida no campo & Nome & Tipo & Tamanho/formato \\
\hline Número do formulário da DN & numerodn & string & 8 caracteres \\
Código do cartório & codcart & string & 4 caracteres \\
Numero do registro em cartório & numregcart & string & 6 caracteres \\
Data do registro em cartório & dtregcart & string & 8 caracteres \\
Código do município do cartório & codmuncart & string & 7 caracteres \\
Local de ocorrência do nascimento & locnasc & string & 1 caractere \\
Código do estabelecimento & codestab & string & 7 caracteres \\
\hline
\end{tabular}




\begin{tabular}{|c|c|c|c|}
\hline Endereço de ocorrência & endnasrc & string & 50 caracteres \\
\hline Código (end. ocorrência) & codendnasc & string & 6 caracteres \\
\hline Numero (end. ocorrência) & numendnasc & string & 6 caracteres \\
\hline Complemento (end. ocorrência) & complnasc & string & 20 caracteres \\
\hline CEP (end. ocorrência) & cepnasc & string & 8 caracteres \\
\hline Bairro (end. ocorrência) & bainasc & string & 30 caracteres \\
\hline Código do bairro (end. ocorrência) & codbainasc & string & 3 caracteres \\
\hline Código do município (end. ocorrência) & codmunnasc & string & 7 caracteres \\
\hline Nome da mãe & nomemae & string & 40 caracteres \\
\hline Número SUS da mãe - RIC & mumsusmae & string & 11 caracteres \\
\hline Idade da mãe & idademae & string & 2 caracteres \\
\hline Confirmação de idade improvável & confidade & string & 1 caractere \\
\hline Estado civil da mãe & estcivmae & string & 1 caractere \\
\hline Escolaridade da mãe & escmae & string & 1 caractere \\
\hline Código de ocupação da mãe & codocupmae & string & 5 caracteres \\
\hline Número de filhos tidos vivos & qtdfilvivo & string & 2 caracteres \\
\hline Número de filhos tidos mortos & qtdfilmort & string & 2 caracteres \\
\hline Endereço de residência & endres & string & 50 caracteres \\
\hline Código (end. residência) & codendres & string & 6 caracteres \\
\hline Numero (end. residência) & numres & string & 6 caracteres \\
\hline Complemento (end. residência) & complres & string & 20 caracteres \\
\hline CEP (end. residência) & cepres & string & 8 caracteres \\
\hline Bairro (end. residência) & baires & string & 30 caracteres \\
\hline Código do bairro (end. residência) & codbaires & string & 3 caracteres \\
\hline Código do município (end. residência) & codmunres & string & 7 caracteres \\
\hline Duração da gestação & gestação & string & 1 caractere \\
\hline Tipo de gravidez & gravidez & string & 1 caractere \\
\hline Tipo de parto & parto & string & 1 caractere \\
\hline Número de consultas pré-natal & consultas & string & 1 caractere \\
\hline Hora do nascimento & horanasc & string & 4 caracteres \\
\hline Data do nascimento & dtnasc & string & 8 caracteres \\
\hline Sexo do recém-nascido & sexo & string & 1 caractere \\
\hline Índice de Apgar $-1^{\circ}$ minuto & apgarl & string & 2 caracteres \\
\hline Índice de Apgar - $5^{\circ}$ minuto & apgar 5 & string & 2 caracteres \\
\hline Raça/cor & racacor & string & 1 caractere \\
\hline Peso ao nascer & peso & string & 4 caracteres \\
\hline Confirmação de peso improvável & confpeso & string & 1 caractere \\
\hline Se identificada anomalia & idanomal & string & 1 caractere \\
\hline Código da anomalia & codanomal & string & 4 caracteres \\
\hline
\end{tabular}




\begin{tabular}{l|ccc}
\hline Número do lote & numerolote & string & 4 caracteres \\
Estado de crítica dos dados & critica & string & 2 caracteres \\
Código de Instalação & codinst & string & 18 caracteres \\
\hline
\end{tabular}

Tabela 4.3: Descrição das características dos campos da ADBA2002.DBF (um registro para cada $\mathrm{DN}$ ).

\begin{tabular}{l|ccc}
\hline Informação contida no campo & Nome & Tipo & Tamanho/formato \\
\hline Número do lote & numerolote & string & 4 caracteres \\
Número do formulário da DN & numerodn & string & 10 caracteres \\
Código da Instalação & instalacao & string & 18 caracteres \\
Se a DN já foi digitada & digitacao & string & 1 caractere \\
\hline
\end{tabular}

Tabela 4.4: Descrição das características dos campos da CTBA2002.DBF (um registro para cada lote).

\begin{tabular}{l|ccc}
\hline Informação contida no campo & Nome & Tipo & Tamanho/formato \\
\hline Número do lote & numerolote & string & 4 caracteres \\
Data de criação do lote & dtcriacao & data & $\mathrm{dd} / \mathrm{mm} / \mathrm{aaaa}$ \\
Data de crítica do lote & dtcritica & data & $\mathrm{dd} / \mathrm{mm} /$ aaaa \\
Data de fechamento do lote & dtfecha & data & $\mathrm{dd} / \mathrm{mm} / \mathrm{aaaa}$ \\
Responsável pela digitação & responsave & string & 30 caracteres \\
Situação do lote & situacao & string & 11 caracteres \\
Quantidade de DNs criadas & qtddn & string & 6 caracteres \\
Quantidade de DNs informadas & dninf & string & 6 caracteres \\
Quantidade de DNs digitadas & dndig & string & 6 caracteres \\
Código da instalação & instalacao & string & 18 caracteres \\
Operação (origem do lote) & operacao & string & 1 caractere \\
Data de recebimento & dtreceb & date & $\mathrm{dd} / \mathrm{mm} /$ aaaa \\
Data de transferência & dttransf & date & dd/mm/aaaa \\
\hline
\end{tabular}




\subsubsection{A manipulação do Banco de Dados}

Ao ser chamado o programa "SINASC - Interface Padrão", uma janela aparecerá (Figura 4.1) dando ao usuário uma série de opções na forma de menus. O menu de "Propriedades" (Figura 4.2) deverá ser selecionado inicialmente para estabelecer "Informações da Instalação", tais como município, código do município e estado. Estas informações são então armazenadas em um arquivo auxiliar do programa e serão usadas para preenchimento automático de campos que serão uma constante para a instalação em questão.

Figura 4.1 - Janela inicial do programa "SINASC - Interface Simplificada".

Figura 4.2 - O menu "Propriedades"

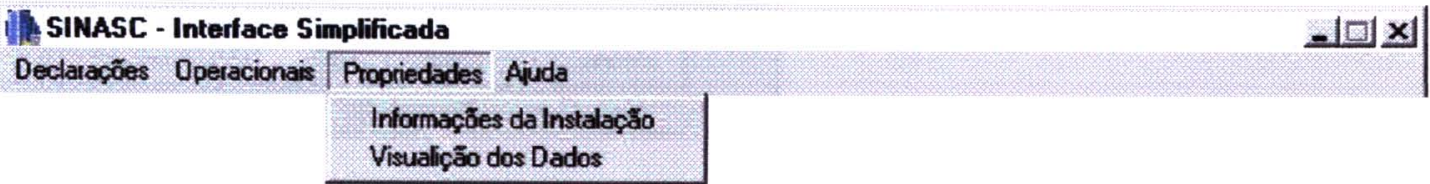

Em seguida, o menu "Declarações" (Figura 4.3), que possui os comandos de criação e manipulação do banco de dados, será utilizado para criar um banco de dados de nascidos vivos para o ano a ser especificado. A opção "Ano de Processamento" aciona uma janela que dá ao usuário a escolha do ano de ocorrência dos nascimentos.

Nesta janela (Figura 4.4), o usuário pode: digitar um ano; incrementar ou decrementar o ano a partir do ano inicialmente sugerido (ano corrente); cancelar a escolha de um ano de processamento. No caso de ser selecionado um ano de 
processamento e acionado o botão "entrar", é iniciada uma busca pela existência de uma tabela no banco de dados que possua por nome o ano em questão. Se esta tabela já existir, ela é aberta para que possa ser manipulada pelo usuário; caso contrário, o usuano e inromado ar mexistencra ae una tavera para aquele ano especincado e questionado sobre a criação ou não de uma nova tabela (Figura 4.5).

Figura 4.3 - O menu "Declarações".

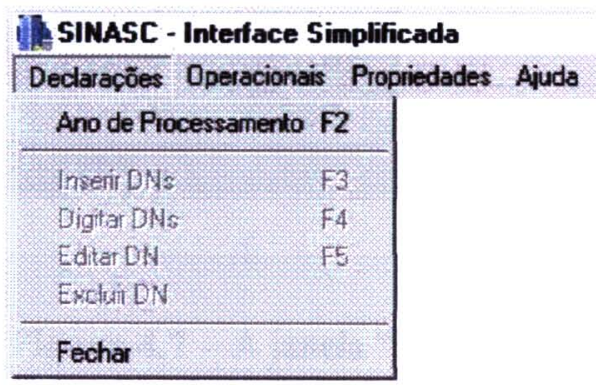

Figura 4.4 - A janela "Ano de processamento".

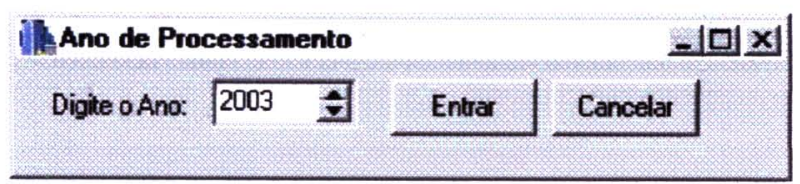

Figura 4.5 - A janela de aviso de criação de uma nova tabela anual.

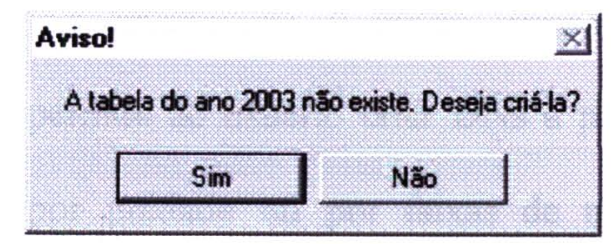

Seja qual for o caso, uma vez determinado o ano de processamento, a barra de identificação do programa é alterada (Figura 4.6) para visualmente informar o usuário da base de dados atualmente em uso. Além disso, opções anteriormente 
indisponíveis de entrada e edição de dados (comparar as Figuras 4.3 e 4.6) permitirão ao usuário criar novas declarações de nascidos vivos (DNs Simplificadas), digitá-las, editá-las ou até mesmo excluí-las.

Figura 4.6 - O menu "Declarações" após escolha do ano de processamento.

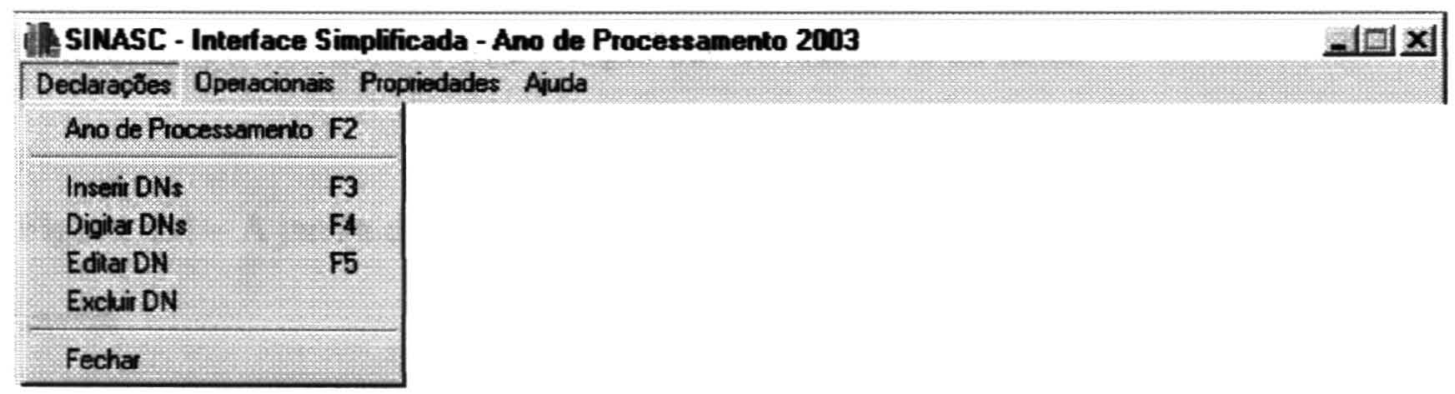

Figura 4.7 - A janela "Inserir DNs".

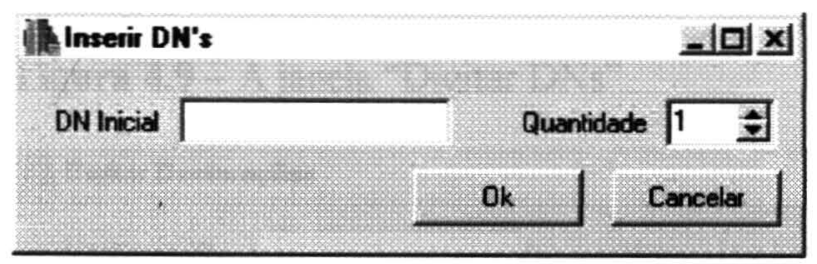

Para que o usuário possa digitar DNs Simplificadas no ano de processamento atualmente em uso será necessário primeiro que ele crie os registros em branco de tais declarações. A opção "Inserir DNs" chama uma nova janela (Figura 4.7) que permite ao usuário criar DNs a partir de sua numeração ${ }^{3}$. Essa criação pode se dar por unidade ou por faixas de numeração, definidas por uma numeração para a primeira DN da faixa e pela quantidade de DNs que a faixa possuirá. O usuário pode

\footnotetext{
${ }^{3}$ Tendo em vista o fato de que o banco de dados do "SINASC - Interface Simplificada" será por fim exportado para o banco do SINASC padrão, a numeração das DNs a ser utilizada no momento da criação destas deve obedecer a critérios rígidos para evitar duplicidade de numeração das DNs. Como cada município recebe blocos de formulários de DNs com faixa de numeraçào pré-definida, um procedimento sugerido é o de separar uma parte de tais formulários para uso de sua numeração exclusivamente pelo "SINASC - Interface Simplificada". O formulário simplificado pode ser grampeado ao formulário padrão do qual herda sua numeração no ato da digitação.
} 
também desistir de criar as DNs por acionar o botão "Cancelar", porém, se autorizar a criação por acionar o botão "Ok", o programa iniciará uma busca pela existência prévia ou não de uma DN com a numeração especificada pela faixa definida. Se encontrar, uma janela de aviso (Figura 4.8) o alertará da duplicidade, abortará a criação daquela DN para evitar problemas com a numeração e perguntará se o usuário deseja continuar com a criação das demais DNs da faixa.

Figura 4.8 - A janela de aviso de duplicação de numeração de DNs.

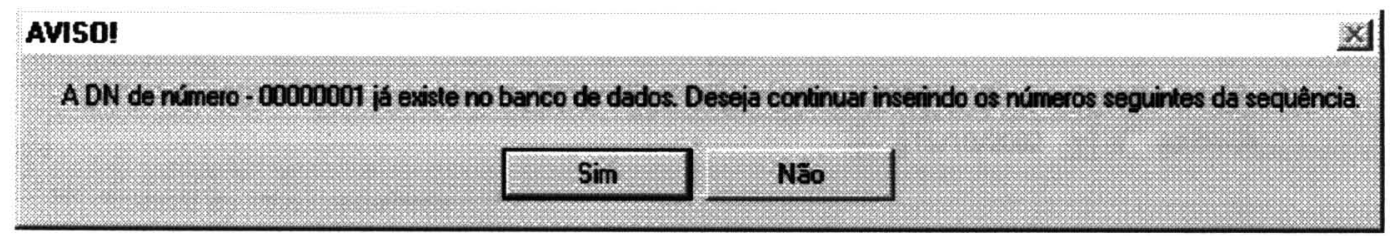

Figura 4.9 - A janela "Digitar DNs".

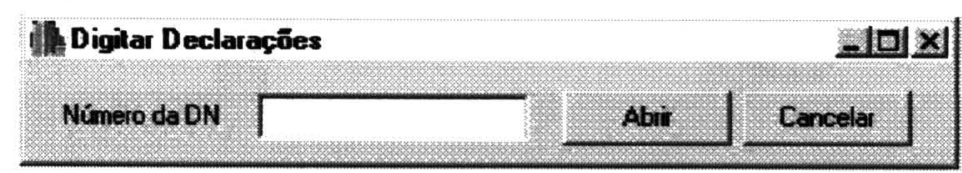

Figura 4.10 - A janela de aviso da inexistência da DN especificada.

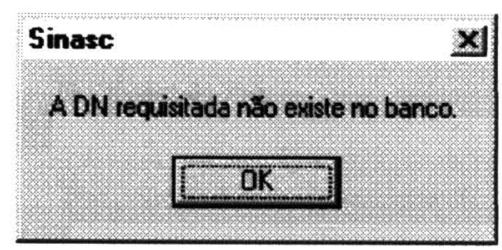

O próximo passo seria o de preencher os registros criados pelo comando "Inserir DNs" usando o comando "Digitar DNs" (conforme Figura 4.6). Uma nova janela (Figura 4.9) aparecerá para que o usuário informe o número da $\mathrm{DN}$ a ser preenchida e, caso o usuário informe um número de DN que não esteja previamente criada, um 
aviso surgirá (Figura 4.10) para informar o usuário de seu erro e, portanto, da necessidade de informar um outro número ou criar a DN com a numeração desejada pelo procedimento anteriormente descrito. Quando um número válido for finalmente informado, uma tela (Figura 4.11) contendo todos os campos referentes àquela DN surgirá para dar a oportunidade ao usuário de preencher o inteiro registro que até então só possuía numeração, ou mesmo de cancelar o procedimento de digitação.

Figura 4.11 - A janela "Digitar DNs".

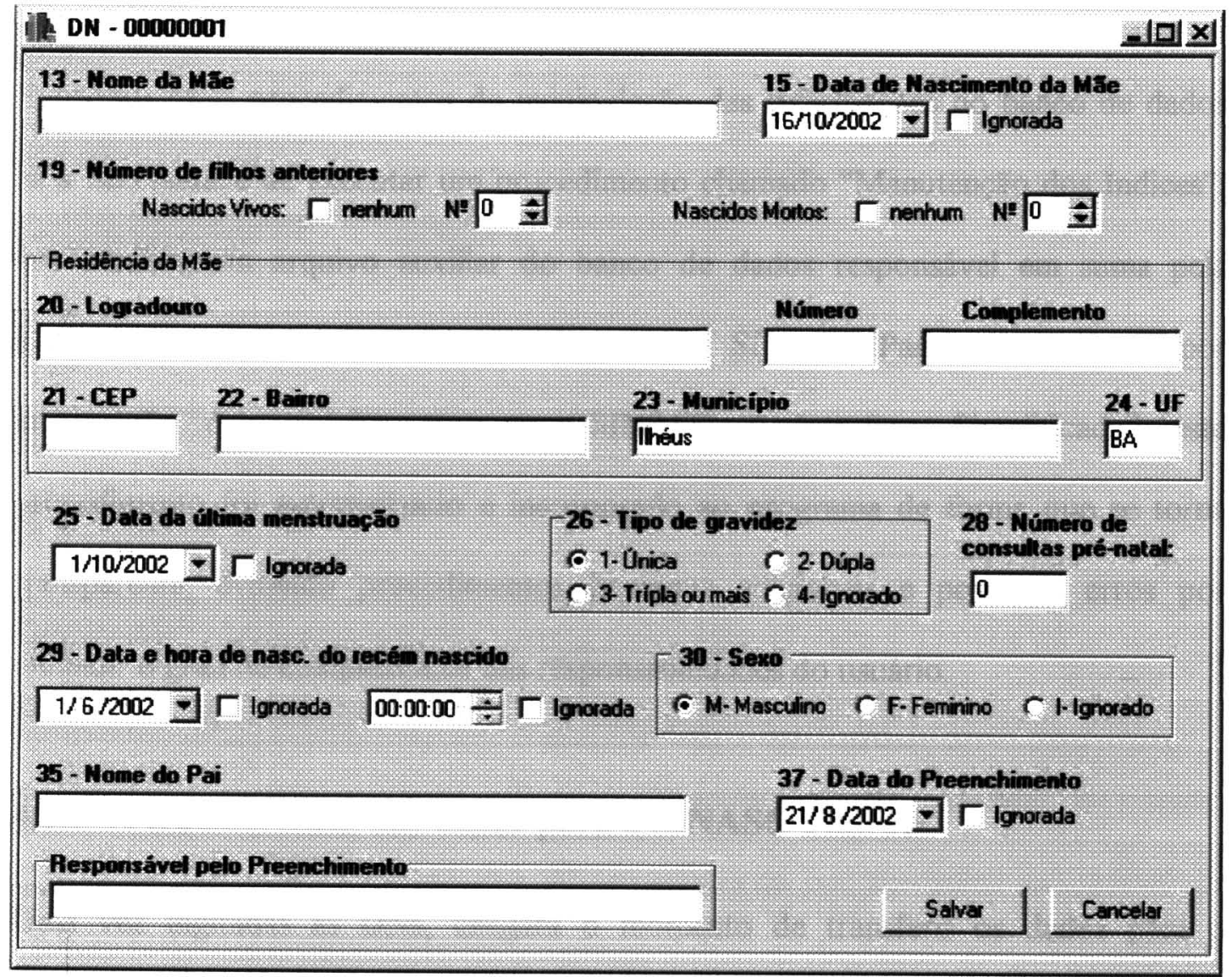

Após preencher todos os campos e acionar o botão salvar (Figura 4.11), a DN estará armazenada no banco de dados. Em vista da possibilidade do usuário desejar alterar algumas informações de uma DN já digitada para efetuar correções, existe um 
comando de "Editar DN" (conforme Figura 4.6) que é similar ao comando de "Digitar DNs", porém oferece a janela dos campos com estes já preenchidos com a informação anterior. Após a alteração dos pontos a serem corrigidos, a informação é sobrescrita no registro daquela DN.

Por fim, prevendo a necessidade eventual de excluir alguma DN do banco de dados (detecção de duplicidade, por exemplo), um comando de "Excluir DN" foi criado, gerando janelas de interação com o usuário nos moldes das Figuras 4.9 e 4.10

Em todos estes procedimentos de manipulação das informações do banco de dados há a necessidade de executar um procedimento chamado "Manutenção dos Índices", que atualiza um arquivo auxiliar do banco de dados responsável em suma pela integridade das informações armazenadas. No SINASC Padrão isso se dá por intervenção do usuário, mas no "SINASC - Interface Simplificada" este procedimento foi automatizado e incorporado ao programa de forma que se torna transparente, evitando procedimentos humanos adicionais e possíveis erros por diminuir o grau de complexidade das responsabilidades do usuário.

\subsubsection{A transferência dos dados para o SINASC Padrão}

Uma vez digitadas as DNs, chegará o momento de transferir os dados para o SINASC Padrão, procedimento denominado no novo programa de "Exportação para - SINASC Padrão". Antes, porém, é preciso adequar os dados a serem transferidos por reuni-los em lotes, procedimento que, além de atender requisitos do SINASC Padrão, possibilitará um controle efetivo dos dados já transferidos, evitando 
confundi-los com os dados digitados mas ainda não exportados. Para realizar tais tarefas, o menu "Operacionais" (Figura 4.12) fornece dois comandos: "Definição de Lotes" e "Exportação para o SINASC Padrão".

Figura 4.12 - O menu “Operacionais”.

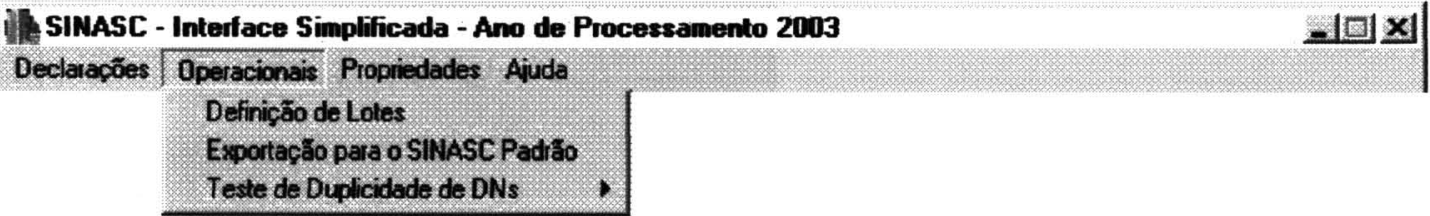

Figura 4.13 - A janela "Definição de Lotes".

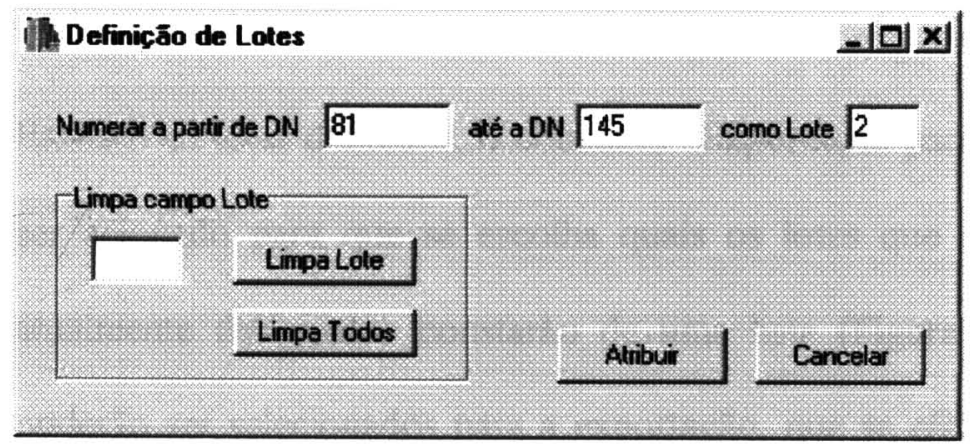

O comando "Definição de Lotes" aciona uma janela (Figura 4.13) que dá ao usuário ferramentas para definir e redefinir os agrupamentos das DNs por lotes. Para criar lotes, o usuário deve especificar a faixa de DNs à qual pretende atribuir um número de lote. A Figura 4.13 exemplifica tal procedimento por preencher os campos de forma que se criaria um lote de número 2 por atribuir este número de lote a cada uma das DNs a partir da de número 81 até a de número 145. Para limpar todos os agrupamentos por lotes o usuário deve acionar o botão "Limpa Todos", porém, se desejar especificar um ou mais lotes a serem eliminados quais formas de agrupamento, deve especifica-los, um a um, no campo dentro do quadro "Limpa 
campo Lote" e acionar o botão "Limpa Lote" para cada lote a ser desfeito.

Figura 4.14 - A janela "Exportação para o SINASC Padrão".

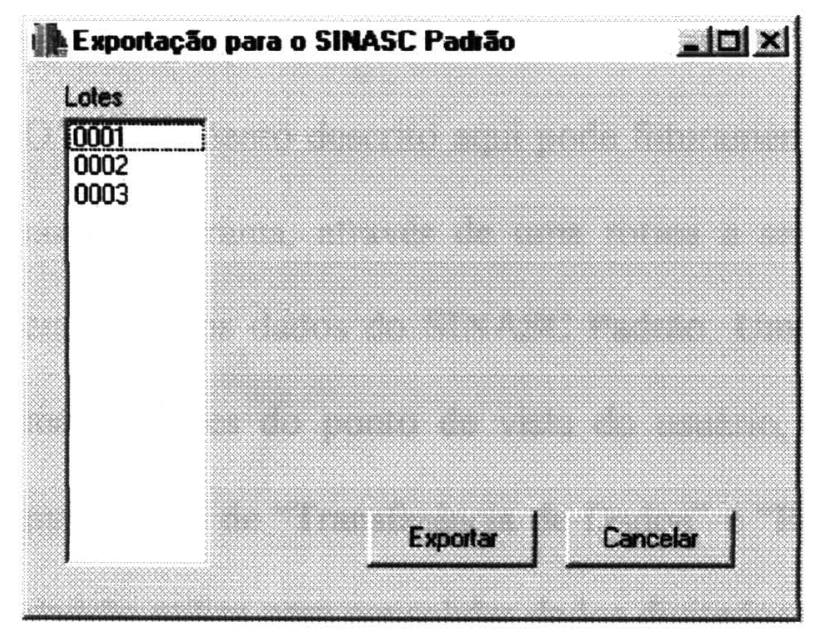

Estando os lotes definidos, o comando "Exportação para o SINASC Padrão" poderá ser acionado para que se escolha quais os lotes que serão exportados. Todos os atualmente designados constarão de uma lista (Figura 4.14) da qual um ou mais poderão ser selecionados para a exportação, que se efetuará quando for acionado o botão "Exportar". Neste ponto, os lotes selecionados serão anexados à tabela no formato do SINASC Padrão que estiver na pasta "dbnovo" existente dentro da pasta do próprio "SINASC - Interface Simplificada". Tal tabela deverá ser copiada manualmente pelo usuário a partir da pasta de dados do próprio SINASC Padrão. Isto pode ser feito através da rotina de "Cópia de Segurança - Base de Dados" do SINASC Padrão, rotina esta que gera um arquivo compactado (base.zip, por exemplo). Este arquivo deve ser descompactado na pasta "dbexterno" mencionada anteriormente para que se possa efetivamente realizar a exportação. Por fim, os arquivos resultantes devem ser compactados no mesmo formato "zip" e tal arquivo deverá ser utilizado para se efetuar, no SINASC Padrão, a rotina de "Restauração de 
Cópia de Segurança - Base de Dados", simulando uma restauração de segurança que na verdade estará sendo usada para receber o banco de dados original acrescido dos dados exportados pelo "SINASC - Interface Simplificada".

O procedimento descrito aqui pode futuramente ser automatizado por se informar ao novo programa, através de uma rotina a ser criada, a pasta em que este poderá encontrar os dados do SINASC Padrão. Uma outra opção, sendo provavelmente a mais simples do ponto de vista do usuário, seria a utilização da exportação pelo mecanismo de "Transferência de Dados" e "Recebimento de Dados" que o SINASC Padrão utiliza para consolidar dados digitados em computadores distintos. Esta opção não foi implementada pelas dificuldades de se fazer engenharia reversa destes procedimentos a ponto de se poder imitá-los e pelo quanto é dispendioso em tempo, tempo este não previsto no cronograma apertado desta tese. Em verdade, a falta de informação sobre a estrutura interna do SINASC Padrão, bem como a grande dificuldade em obter informações descritivas suficientes, geraram grandes dificuldades no estabelecimento de padrões de comunicação entre os dois programas de computador, restando ao programador somente métodos de engenharia reversa e de "tentativa e erro".

\subsubsection{As rotinas de teste de DNs em duplicidade}

A duplicidade de DNs ocorre quando dois registros distintos, duas DNs, são criados para um mesmo nascido vivo. Como este projeto reúne dados sobre nascidos vivos captados de duas fontes distintas e potencialmente redundantes, há a necessidade de testar e identificar duplicidades nos dados reunidos. Em vista da possibilidade de 
captação duplicada de um mesmo evento pelos formulários simplificados, foi criada uma rotina de "Teste de Duplicidade de DNs" tanto nos dados do simplificado como nos dados reunidos (Figura 4.15).

Figura 4.15 - O submenu "Teste de Duplicidade de DNs".

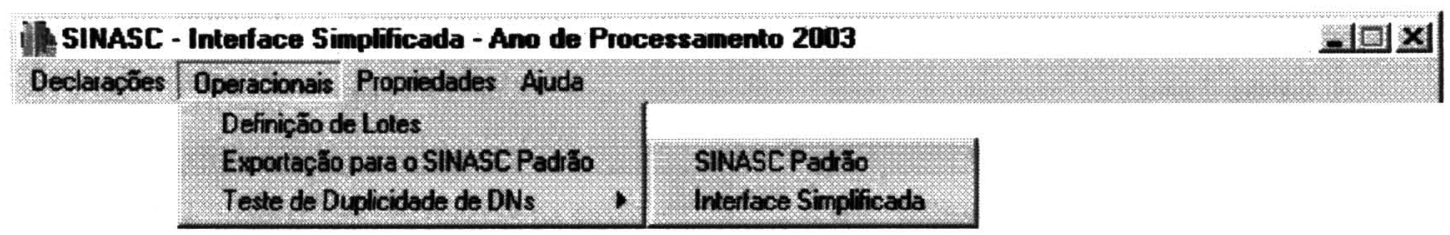

Foi criada uma única interface para qualquer dos dois testes (Figura 4.16), sendo que, a depender de que alternativa do submenu "Teste de Duplicidade de DNs" for marcada, o quadro "Banco de Dados" virá com uma de suas opções pré-selecionadas. Uma vez selecionadas as opções de "Campos de Busca", campos que terão seus conteúdos comparados, um clique no botão "Listar Duplicatas" listará todos os pares de possíveis DNs que se referem ao mesmo recém nascido. Por sua vez, um clique em qualquer dos pares listará o conteúdo dos dois registros para uma confirmação visual da aparente redundância.

Se o usuário identificar uma duplicação, poderá fazer nota do número das DNs em duplicidade para poder excluir uma delas usando para isso o próprio SINASC Padrão. Futuramente, uma rotina de exclusão a partir desta janela (Figura 4.16) poderá ser criada para tornar mais prática esta tarefa. 
Figura 4.16 - A janela "Busca de Duplicatas no Banco de Dados".

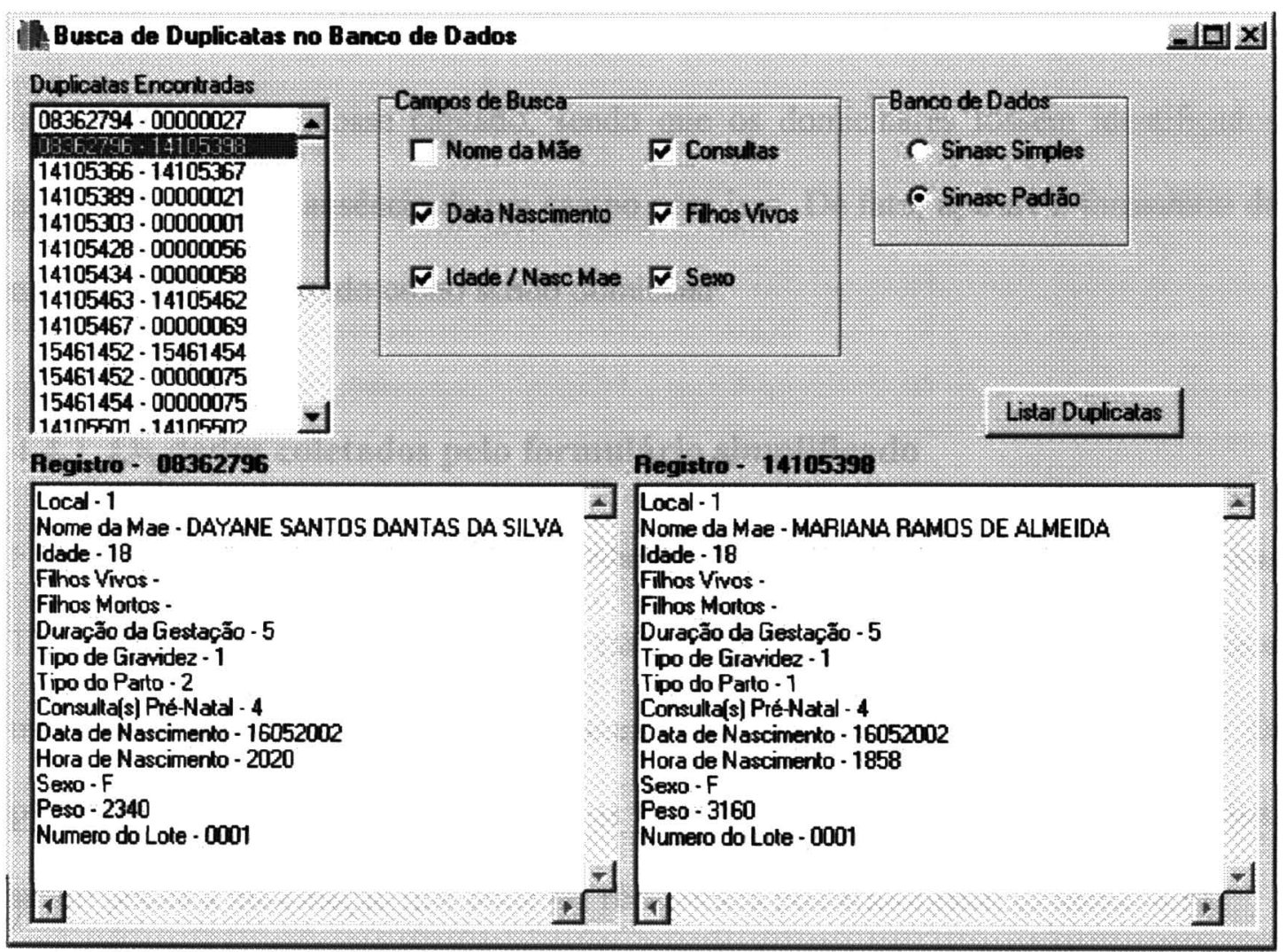

\subsection{Avaliação dos dados obtidos e das variáveis utilizadas}

Embora o período de referência de coleta de dados desta pesquisa tenha sido de 01/05/2002 a 31/07/2002 (três meses), a intenção original era fazê-lo nos meses de abril, maio e junho. Também era intenção original captar apenas nascidos vivos por meio de partos domiciliares, ao invés de obter dados sobre os nascidos vivos hospitalares e domiciliares. Porém, as primeiras semanas de coleta do mês de abril só geraram um único parto domiciliar, havendo perspectiva para o mês de maio de mais apenas um outro evento destes. Tal situação surpreendente se deve ao excelente trabalho de supervisão e pré-encaminhamento das gestantes às unidades de saúde realizado em Ilhéus, reduzindo o número de partos domiciliares grandemente. 
Como um volume tão pequeno de informações inviabilizaria esta pesquisa, o período de coleta foi relocado para de maio a julho e instruções foram dadas no sentido de que qualquer parto fosse captado, sendo que os domiciliares fossem identificados como tais devido à ausência de um campo para isso. De fato, apenas o formulário de número 89 foi registrado como sendo domiciliar.

\subsubsection{Os dados coletados pelo formulário simplificado}

Foram coletados 176 formulários distribuídos conforme Tabela 4.5. Destes apenas 170 foram considerados válidos, sendo que 5 estavam fora do período de referência e um deles estava sem a data de nascimento do nascido vivo. Além desta falha de preenchimento, foram detectados outros campos em branco em vários formulários, sendo pouca a informação que pode ser recuperada posteriormente. (Tabelas 4.6).

Tabela 4.5: Distribuição dos formulários coletados segundo mês de ocorrência do evento, Ilhéus, 2002

\begin{tabular}{l|cc}
\hline Mês de ocorrência do evento & Número & Percentual \\
\hline Abril & 5 & $2,9 \%$ \\
Maio & 64 & $36,3 \%$ \\
Junho & 54 & $30,7 \%$ \\
Julho & 52 & $29,5 \%$ \\
Ignorado & 1 & $0,6 \%$ \\
\hline Total & 176 & $100,0 \%$ \\
\hline
\end{tabular}


Tabela 4.6: Distribuição dos 170 formulários válidos coletados segundo o preenchimento de algumas de suas variáveis, Ilhéus, 2002.

\begin{tabular}{l|rrrrrr}
\hline \multirow{2}{*}{\multicolumn{1}{c}{ Variável }} & \multicolumn{3}{c}{ Preenchida } & \multicolumn{2}{c}{ Não preenchida } & \multirow{2}{*}{ Total } \\
\cline { 2 - 5 } & $\mathrm{N}^{\mathbf{o}}$ & $\%$ & $\mathrm{~N}^{\mathbf{0}}$ & $\%$ & \\
\hline Sexo do recém-nascido & 169 & 99,4 & 1 & 0,6 & 170 \\
Tipo de Gravidez & 166 & 97,6 & 4 & 2,4 & 170 \\
Filhos anteriores nasc. vivos & 163 & 95,9 & 7 & 4,1 & 170 \\
Data de nascimento da mãe & 154 & 90,6 & 16 & 9,4 & 170 \\
Consultas pré-natal & 152 & 89,4 & 18 & 10,6 & 170 \\
Data da última menstruação & 142 & 83,5 & 28 & 16,5 & 170 \\
Nome do Pai & 136 & 80,0 & 34 & 20,0 & 170 \\
Hora do nascimento & 124 & 72,9 & 46 & 27,1 & 170 \\
Filhos anteriores nasc. mortos & 99 & 58,2 & 71 & 41,8 & 170 \\
\hline
\end{tabular}

Depois de digitar todas as $170 \mathrm{DNs}$ simplificadas no programa, foram testadas pela rotina de "Busca de Duplicatas no Banco de Dados" Simplificado. Como nenhuma redundância foi encontrada, concluiu-se que as $170 \mathrm{DNs}$ são referentes a eventos distintos. Em seguida, a Tabela 4.6 foi gerada com o auxílio do programa estatístico TabWin, versão 2.2. Para tornar possível o uso das tabelas do "SINASC - Interface Simplificada" pelo TabWin, elas foram convertidas de seu formato Paradox para o formato Dbase.

\subsubsection{Análise do preenchimento do formulário simplificado.}

O preenchimento ou não das variáveis do formulário simplificado aplicado nesta pesquisa (Tabela 4.6) pode ser classificado como bom, satisfatório (regular) ou ruim à luz de um estudo sobre declarações de nascidos vivos publicado em 1996 (MELLO JORGE e col. 1996) que discute faixas de percentual de preenchimento das variáveis da DN e as classifica conforme Tabela 4.7. 
Tabela 4.7: Distribuição de variáveis da DN Simplificada por faixas percentuais de não preenchimento.

\begin{tabular}{|c|c|c|}
\hline Não preenchimento (\%) & Avaliação & Variáveis Quantificadas \\
\hline 0 a 9,9 & bom & $\begin{array}{c}\text { tipo de gravidez, filhos tidos nascidos } \\
\text { vivos, } \\
\text { sexo, data de nascimento da mãe }\end{array}$ \\
\hline 10 a 19,9 & regular & $\begin{array}{c}\text { consultas pré-natal, } \\
\text { data da última menstruação }\end{array}$ \\
\hline $20 e^{+}$ & ruim & $\begin{array}{l}\text { hora do nascimento nome do pai, } \\
\text { filhos tidos nascidos mortos }\end{array}$ \\
\hline
\end{tabular}

A tabela demonstra a boa qualidade do preenchimento de um formulário ao qual os agentes do PACS não estavam familiarizados até o início da pesquisa. Mesmo aqueles que já conheciam o formulário padrão tiveram de enfrentar mudanças no formato de algumas varáveis.

A data de nascimento da mãe no lugar da idade teve um bom preenchimento e é uma informação mais precisa. Dos $9,4 \%$ de formulários sem este dado, a maioria foi, de fato, preenchida equivocadamente com a mesma informação do campo 29 , data de nascimento do recém-nascido. Com instruções direcionadas a esclarecer os agentes do PACS a respeito dessa variável ser na verdade a data de nascimento da mãe em substituição à idade desta, esse percentual tende a ser bem menor.

Quanto ao número de filhos anteriores, a utilização de um marcador para nenhum diferenciou melhor os ignorados do valor zero. Os "Nascidos Vivos" tiveram um 
bom nível de preenchimento e os "Nascidos Mortos" tiveram um nivel ruim de preenchimento, provavelmente pelo fato de ser com maior freqüência nulo e ter assim seu preenchimento ignorado, o que poderia ser melhorado pelo uso correto do marcador de nenhum. Além disso, os campos do número de filhos tidos anteriores nascidos vivos e nascidos mortos são de dificil entendimento para os responsáveis pelo preenchimento, causando o baixo preenchimento do "Nascidos Mortos" e a má qualidade na informação preenchida em ambos. Por exemplo, achar que o campo "Nascidos Vivos" envolve somente os que ainda estão vivos até então ou a inclusão da gestação atual no número informado.

A data da última menstruação teve um nível regular de preenchimento, o que pode ser considerado muito bom para uma coleta tardia e não hospitalar, e é mais precisa do que faixas de semanas gestacionais.

O nivel de preenchimento do tipo de gravidez foi bom e o do número de consultas pré-natal, ao invés de faixas de número de consultas, foi regular.

A data de nascimento do recém-nascido teve um bom preenchimento, visto que apenas uma DN foi descartada por não preenchimento deste dado essencial à digitação do formulário. Já a hora de nascimento teve um nível ruim, fato esperado por ser um registro tardio e ser um dado não tão marcante quanto a data de nascimento

Por fim, o Sexo teve um bom nivel de preenchimento e o Nome do Pai teve um nível ruim, mas a obtenção de $80 \%$ de preenchimento mostra que sua coleta é possivel. 


\subsubsection{Os dados coletados pelo SINASC Padrão}

Para a realização de uma análise comparativa, foram obtidos na Secretaria Municipal de Saúde de Ilhéus os dados do SINASC Padrão referentes ao mesmo período de coleta dos formulários simplificados, conforme definido no tópico "3.2 População de Estudo e Periodo de Referência" deste documento.

Também de acordo com este tópico, para minimizar perdas devidas a atrasos, os dados do SINASC seriam complementados com informações colhidas até 30/09/2002, ou seja, dois meses após o último dia do período de coleta. Devido ao grande atraso constatado, conforme relatado no tópico 4.1 , no efetivo recebimento da SMS dos formulários das unidades de saúde depois de gerados por estas, este prazo foi estendido em mais um mês. Portanto, ao final do mês de outubro foi solicitada e recebida uma cópia de segurança de todos os eventos digitados no SINASC Padrão, eventos estes ocorridos no ano de 2002 .

Tabela 4.8: Distribuição das DNs Padrão por mês ocorrência do nascimento no ano de 2002 .

\begin{tabular}{l|cc}
\hline Mês de ocorrência do nascimento & Número & Percentual \\
\hline lote 1 - maio & 131 & 29,4 \\
lote 2 - junho & 137 & 30,8 \\
lote 3 - julho & 177 & 39,8 \\
\hline Total & 445 & 100,0 \\
\hline
\end{tabular}


De posse destes dados, foi criada uma rotina de seleção ${ }^{4}$ para criar novas tabelas que só possuíssem eventos ocorridos no período de referência, ou seja, nos meses de maio, junho e julho. Os dados estavam originalmente dispostos em lotes de $50 \mathrm{DNs}$, sendo um total de 34 lotes completos e um incompleto. Após selecionados, foram obtidos 446 registros agrupados em três lotes numerados de 1 a 3 . Após a realização de um teste de duplicidade nos dados selecionados, foram encontrados 4 casos de gêmeos e um caso de duplicidade, sendo este entre as DNs 14105529 e 14105553 do lote 2 , reduzindo o total para 445 registros (Tabela 4.7).

\subsubsection{A reunião dos dados}

Para os dados coletados pelo "SINASC - Interface Simplificada" foram definidos três lotes à semelhança do que foi feito para os dados recebidos do SINASC Padrão (Tabela 4.9), sendo que sua numeração escolhida foi de 4 a 6 para diferenciá-los quando viessem a ser reunidos.

Tabela 4.9: Distribuição das DNs Simplificadas por mês ocorrência do nascimento no ano de 2002.

\begin{tabular}{l|cc}
\hline Mês de ocorrência do nascimento & Número & Percentual \\
\hline lote 4 - maio & 64 & 37,6 \\
lote 5 - junho & 54 & 31,8 \\
lote 6 - julho & 52 & 30,6 \\
\hline Total & 170 & 100,0 \\
\hline
\end{tabular}

\footnotetext{
${ }^{4}$ Esta rotina, embora faça parte do programa "SINASC - Interface Simplificada", não se encontra visivelmente disponivel para o usuário por aparentemente não ter utilidade para qualquer município que futuramente se dispuser a utilizá-lo como complemento ao SINASC Padrão. Em caso de haver necessidade, uma futura disponibilização pode ser implementada.
} 
Após a reunião dos dados pela rotina de "Exportação para o SINASC Padrão", um novo teste de duplicidade, ou redundância, foi feito sobre as então 615 DNs (Tabela 4.10). Depois de sucessivos testes, foram eliminadas 74 DNs dos lotes 4,5 e 6 que eram redundantes em relação aos lotes 1,2 e 3 (Tabela 4.11).

Tabela 4.10: Distribuição das DNs Reunidas por lote antes da eliminação de duplicidades.

\begin{tabular}{l|cc}
\hline Mês de ocorrência do nascimento & Número & Percentual \\
\hline lote 1 - maio & 131 & 21,3 \\
lote 2 - junho & 137 & 22,3 \\
lote 3 - julho & 177 & 28,8 \\
lote 4 - maio & 64 & 10,4 \\
lote 5 - junho & 54 & 8,8 \\
lote 6 - julho & 52 & 8,4 \\
\hline Total & 615 & 100,0 \\
\hline
\end{tabular}

O primeiro teste foi feito com todas as opções marcadas exceto o "Nome da Mãe", resultando na eliminação de 7 DNs. Desmarcando "Consultas", outras 9 DNs duplicadas foram encontradas. Um terceiro teste sem "Filhos Vivos" eliminou outras 37 DNs e um último teste sem "Idade Mãe", ou seja, só com "Data de Nascimento" e "Sexo", eliminou as últimas 21 DNs. Testes adicionais foram feitos sem encontrar novas duplicações, entre eles: com "Data Nascimento" e "Idade Mãe"; com "Data Nascimento", "Consultas" e "Filhos Vivos"; somente "Data Nascimento".

Desta forma, $43,5 \%$ dos dados originados pelos formulários simplificados foram desprezados por já existirem nos dados obtidos pela SMS de Ilhéus, restando significativos $56,5 \%$ como contribuição para o banco de dados reunido. Somando as 
três contribuições percentuais dos lotes 4 a 6 da Tabela 4.11, os dados coletados pelo PACS totalizam $17,7 \%$ do total dos dados reunidos, ou, sobre outro ponto de vista, um ganho de $21,6 \%$ de informação por se dividir os 96 registros do "SINASC Interface Simplificada" pelos 445 registros do SINASC Padrão.

Tabela 4.11: Distribuição das DNs Reunidas por lote depois da eliminação de duplicidades.

\begin{tabular}{l|cc}
\hline Mês de ocorrência do nascimento & Número & Percentual \\
\hline lote 1 - maio & 131 & 24,2 \\
lote 2 - junho & 137 & 25,3 \\
lote 3 - julho & 177 & 32,7 \\
lote 4 - maio & 41 & 7,6 \\
lote 5 - junho & 29 & 5,4 \\
lote 6 - julho & 26 & 4,8 \\
\hline Total & 541 & 100,0 \\
\hline
\end{tabular}

\subsubsection{Análise comparativa dos dados}

Com o objetivo de analisar o perfil dos dados, comparando os coletados pelo "SINASC - Interface Simplificada" com os recebidos do SINASC Padrão, foram levantadas algumas tabelas pela aplicação do programa "TabWin" nas DNs mencionadas na tabela 4.11 .

As variáveis escolhidas foram a idade da mãe, as semanas gestacionais, consultas pré-natal e número de filhos tidos. Estas foram variáveis utilizadas em um formato diferente e mais informativo e enfrentaram problemas de preenchimento. 
A comparação entre os dados de "idade da mãe" obtidos no SINASC Padrão e Simplificado encontram-se nas tabelas 4.12 e 4.13. Os dados da Tabela 4.12 mostram que a proporção de ignorados foi maior na versão simplificada, e que esta diferença é estatisticamente significante. Possivelmente este resultado se deve a dois fatores: a) Ao se pedir a data de nascimento da mãe, esta foi confundida com a data de nascimento do recém-nascido; b) Quando a exata data era ignorada, uma data aproximada ou mesmo a idade aproximada poderia ter sido registrada, mas não o foi. Entretanto este problema pode ser facilmente solucionado por meio de um treinamento adequado dos agentes comunitários

Tabela 4.12: Distribuição das DNs padrão e simplificada segundo preenchimento da variável Idade da Mãe.

\begin{tabular}{l|rrrr|rr}
\hline \multirow{2}{*}{ Idade da Mãe } & \multicolumn{2}{c}{ Padrão } & \multicolumn{2}{c}{ Simplificado } & \multicolumn{2}{c}{ TOTAL } \\
\cline { 2 - 7 } & \multicolumn{1}{c}{$\mathrm{N}^{\mathrm{o}}$} & $\%$ & $\mathrm{~N}^{\mathrm{o}}$ & \multicolumn{1}{c}{$\%$} & \multicolumn{1}{c}{$\mathrm{N}^{\mathbf{0}}$} & \multicolumn{1}{c}{$\%$} \\
\hline Preenchida & 433 & 97,3 & 86 & 89,6 & 519 & 95,9 \\
Não-preenchida & 12 & 2,7 & 10 & 10,4 & 22 & 4,1 \\
\hline TOTAL & 445 & 100,0 & 96 & 100,0 & 541 & 100,0 \\
\hline \multicolumn{1}{c}{$\chi^{2}=21,76 ; \mathrm{p}=0,0000$} & & & & &
\end{tabular}

Tabela 4.13: Distribuição das DNs padrão e simplificada segundo Idade da Mãe, excluidas as ignoradas.

\begin{tabular}{|c|c|c|c|c|c|c|}
\hline \multirow{2}{*}{$\begin{array}{l}\text { Idade da Mãe } \\
\text { (em anos) }\end{array}$} & \multicolumn{2}{|c|}{ Padrão } & \multicolumn{2}{|c|}{ Simplificado } & \multicolumn{2}{|c|}{ TOTAL } \\
\hline & $\mathrm{N}^{\circ}$ & $\%$ & $\mathrm{~N}^{\circ}$ & $\%$ & $\mathrm{~N}^{\circ}$ & $\%$ \\
\hline Menor que 15 & 7 & 1,6 & 3 & 3,5 & 10 & 1,9 \\
\hline 15 a 19 & 140 & 32,3 & 22 & 25,6 & 162 & 31,2 \\
\hline 20 a 34 & 265 & 61,2 & 56 & 65,1 & 321 & 61,9 \\
\hline 35 ou mais & 21 & 4,9 & 5 & 5,8 & 26 & 5,0 \\
\hline TOTAL & 433 & 100,0 & 86 & 100,0 & 519 & 100,0 \\
\hline
\end{tabular}


Os dados da tabela 4.13 mostram que não há diferença estatisticamente significante quanto à distribuição etária das mães entre os nascidos vivos captados pela versão simplificada e os captados pela versão padrão.

Em relação à idade gestacional verificou-se, novamente que a proporção de ausência de informação foi mais elevada na versão simplificada (Tabela 4.14) e que esta é estatisticamente significativa.

Tabela 4.14: Distribuição das DNs padrão e simplificada segundo preenchimento da variável Duração da Gestação.

\begin{tabular}{l|rrrrrrr}
\hline \multirow{2}{*}{ Duração da Gestação } & \multicolumn{2}{c}{ Padrão } & \multicolumn{2}{c}{ Simplificado } & \multicolumn{2}{c}{ TOTAL } \\
\cline { 2 - 7 } & \multicolumn{1}{c}{$\mathrm{N}^{\mathbf{o}}$} & $\%$ & $\mathrm{~N}^{\circ}$ & $\%$ & \multicolumn{1}{c}{$\mathrm{N}^{\mathbf{0}}$} & $\%$ \\
\hline Preenchido & 440 & 98,9 & 78 & 81,2 & 518 & 95,8 \\
Não-preenchido & 5 & 1,1 & 18 & 18,8 & 23 & 4,2 \\
\hline TOTAL & 445 & 100,0 & 96 & 100,0 & 541 & 100,0 \\
\hline \multicolumn{2}{c}{$\chi^{2}=274,90 ; \mathrm{p}=0,0000$}
\end{tabular}

$\chi^{2}=274,90 ; p=0,0000$

Apesar da proporção do elevado não preenchimento $(18,8 \%)$ e este se encontrar acima de $10 \%$, decidiu-se considerar a idade gestacional nas categorias de pré-termo e não pré-termo (Tabela 4.15), conforme proposto por Mello Jorge e col. 1993. Observou-se uma diferença estatisticamente significativa de nascimentos de prétermo entre aqueles que foram captados pela versão simplificada. 
Esse resultado indica que a forma de obter a duração da gestação por meio da variável "data da última menstruação" pode ter maior sensibilidade para a captação dessa informação, resultando desta maneira em uma maior freqüência de nascimentos prematuros. Esse achado é semelhante aos obtidos por Silva e col. 2001 e Crook e col. 2003 mostraram que o SINASC subestima a prevalência de nascimentos de pré-termo. Vale notar que foi possível obter essa informação fora do ambiente hospitalar e por meio de agentes comunitários o que indica que é possivel utilizar a data da última menstruação também no SINASC Padrão e que seu emprego poderia resultar em informações mais fidedignas.

Tabela 4.15: Distribuição das DNs padrão e simplificada segundo Duração da Gestação

\begin{tabular}{l|rrrrrrr}
\hline \multirow{2}{*}{ Duração da Gestação } & \multicolumn{2}{c}{ Padrão } & \multicolumn{2}{c}{ Simplificado } & \multicolumn{2}{c}{ TOTAL } \\
\cline { 2 - 7 } & \multicolumn{1}{c}{$\mathrm{N}^{\mathrm{o}}$} & $\%$ & $\mathrm{~N}^{\circ}$ & \multicolumn{1}{c}{$\%$} & \multicolumn{1}{c}{$\mathrm{N}^{\mathrm{o}}$} & \multicolumn{1}{c}{$\%$} \\
\hline Pré-termo & 20 & 4,5 & 16 & 20,5 & 36 & 6,9 \\
Não pré-termo & 420 & 95,5 & 62 & 79,5 & 482 & 93,1 \\
\hline TOTAL & 440 & 100,0 & 78 & 100,0 & 518 & 100,0 \\
\hline \multicolumn{1}{c}{$\chi^{2}=45,83 ; \mathrm{p}=0,0000}$.
\end{tabular}

$\mathrm{Na}$ análise seguinte, verificou-se que houve um maior não preenchimento $(13,5 \%) \mathrm{da}$ variável pré-natal na DN simplificada que na DN padrão (Tabela 4.16) e que esta diferença foi estatisticamente significativa, mostrando mais uma vez a necessidade de maior treinamento dos agentes comunitários para a aprimorar a captação destas informações. 
Tabela 4.16: Distribuição das DNs padrão e simplificadas por preenchimento de Consultas Pré-natal.

\begin{tabular}{l|rrrr|rr}
\hline \multicolumn{1}{c}{ Consultas } & \multicolumn{2}{c}{ Padrão } & \multicolumn{2}{c}{ Simplificado } & \multicolumn{2}{c}{ TOTAL } \\
\cline { 2 - 7 } \multicolumn{1}{c}{ Pré-natal } & \multicolumn{1}{c}{$\mathrm{N}^{\mathrm{o}}$} & $\%$ & \multicolumn{1}{c}{$\mathrm{N}^{\mathrm{o}}$} & $\%$ & \multicolumn{1}{c}{$\mathrm{N}^{\mathbf{2}}$} & \multicolumn{1}{c}{$\%$} \\
\hline Preenchido & 410 & 92,1 & 83 & 86,5 & 493 & 91,1 \\
Não-preenchido & 35 & 7,9 & 13 & 13,5 & 48 & 8,9 \\
\hline TOTAL & 445 & 100,0 & 96 & 100,0 & 541 & 100,0 \\
\hline
\end{tabular}

$\chi^{2}=4,20 ; p=0,0404$.

Tabela 4.17: Distribuição das DNs padrão e simplificadas por ocorrência de Consultas Pré-natal

\begin{tabular}{|c|c|c|c|c|c|c|}
\hline \multirow{2}{*}{$\begin{array}{l}\text { Consultas } \\
\text { Pré-natal }\end{array}$} & \multicolumn{2}{|c|}{ Padrão } & \multicolumn{2}{|c|}{ Simplificado } & \multicolumn{2}{|c|}{ TOTAL } \\
\hline & $N^{0}$ & $\%$ & $N^{\circ}$ & $\%$ & $\mathrm{~N}^{\mathbf{0}}$ & $\%$ \\
\hline Fez pré-natal & 385 & 93,9 & 79 & 95,2 & 464 & 94,1 \\
\hline Não fez pré-natal & 25 & 6,1 & 4 & 4,8 & 29 & 5,9 \\
\hline TOTAL & 410 & 100,0 & 83 & 100,0 & 493 & 100,0 \\
\hline
\end{tabular}

$\chi^{2}=0,24 ; p=0,6242$.

A Tabela 4.17 mostra que ao se dicotomizar a variável pré-natal em sim e não a pequena diferença encontrada entre a população de nascidos vivos captados pelo SINASC Padrão e Simplificado não foi estatisticamente significante. No entanto ao se analisar o número de consultas realizadas (Tabela 4.18), observa-se há diferenças significativas da distribuição de consultas entre as duas populações estudadas, com uma menor proporção de mães com 7 consultas ou mais, que é considerado como adequado. 
Tabela 4.18: Distribuição das DNs padrão e simplificadas segundo número de consultas pré-natal.

\begin{tabular}{l|rrrr|rr}
\hline \multicolumn{1}{c}{ Consultas } & \multicolumn{2}{c}{ Padrão } & \multicolumn{2}{c}{ Simplificado } & \multicolumn{2}{c}{ TOTAL } \\
\cline { 2 - 7 } \multicolumn{1}{c}{ Pré-natal } & \multicolumn{1}{c}{$\mathrm{N}^{\mathbf{0}}$} & $\%$ & \multicolumn{1}{c}{$\mathrm{N}^{\mathbf{0}}$} & \multicolumn{1}{c}{$\%$} & \multicolumn{1}{c}{$\mathrm{N}^{\mathbf{0}}$} & \multicolumn{1}{c}{$\%$} \\
\hline Nenhuma & 25 & 6,1 & 4 & 4,8 & 29 & 5,9 \\
l a 3 & 96 & 23,4 & 20 & 24,1 & 116 & 23,5 \\
4 a 6 & 112 & 27,3 & 39 & 47,0 & 151 & 30,6 \\
7 ou mais & 177 & 43,2 & 20 & 24,1 & 197 & 40,0 \\
\hline TOTAL & 410 & 100,0 & 83 & 100,0 & 493 & 100,0 \\
\hline
\end{tabular}
$\chi^{2}=18,18 ; p=0,0000$

Quanto às variáveis "Filhos tidos anteriormente vivos" $\mathrm{e}$ "Filhos tidos anteriormente mortos", a proposta de acrescentar ao formulário, para cada uma delas, uma casela com denominação "nenhum", a ser preenchida se a informação for zero, permitiu diferenciar preenchimento de nenhum de "informação ignorada". A inexistência no banco Padrão de informação ignorada em ambas as variáveis (Tabelas 4.19 e 4.20) pode ser indício da vulnerabilidade do formulário Padrão a este erro, resultando no também visivel crescimento do número de formulários com valor "nenhum" (Tabela 4.21).

Tabela 4.19: Distribuição das DNs padrão e simplificadas segundo preenchimento de número de filhos tidos vivos.

\begin{tabular}{|c|c|c|c|c|c|c|}
\hline \multirow{2}{*}{$\begin{array}{c}\text { Filhos } \\
\text { tidos vivos }\end{array}$} & \multicolumn{2}{|c|}{ Padrão } & \multicolumn{2}{|c|}{ Simplificado } & \multicolumn{2}{|c|}{ TOTAL } \\
\hline & $N^{0}$ & $\%$ & $\mathrm{~N}^{\mathrm{o}}$ & $\%$ & $\mathrm{~N}^{\circ}$ & $\%$ \\
\hline Não ignorado & 445 & 100,0 & 93 & 96,9 & 538 & 99,4 \\
\hline Ignorado & 0 & 0,0 & 3 & 3,1 & 3 & 0,6 \\
\hline TOTAL & 445 & 100,0 & 96 & 100,0 & 541 & 100,0 \\
\hline
\end{tabular}


Tabela 4.20: Distribuição das DNs padrão e simplificadas por preenchimento de número de filhos tidos mortos.

\begin{tabular}{|c|c|c|c|c|c|c|}
\hline \multirow{2}{*}{$\begin{array}{c}\text { Filhos } \\
\text { tidos mortos }\end{array}$} & \multicolumn{2}{|c|}{ Padrão } & \multicolumn{2}{|c|}{ Simplificado } & \multicolumn{2}{|c|}{ TOTAL } \\
\hline & $\mathrm{N}^{\mathrm{o}}$ & $\%$ & $N^{\circ}$ & $\%$ & $N^{0}$ & $\%$ \\
\hline Não ignorado & 445 & 100,0 & 57 & 59,4 & 503 & 93,0 \\
\hline Ignorado & 0 & 0,0 & 39 & 40,6 & 39 & 7,0 \\
\hline TOTAL & 445 & 100,0 & 96 & 100,0 & 541 & 100,0 \\
\hline
\end{tabular}

Tabela 4.21: Distribuição das DNs padrão e simplificadas por número de filhos tidos vivos.

\begin{tabular}{|c|c|c|c|c|c|c|}
\hline \multirow{2}{*}{$\begin{array}{c}\text { Filhos } \\
\text { tidos vivos }\end{array}$} & \multicolumn{2}{|c|}{ Padrão } & \multicolumn{2}{|c|}{ Simplificado } & \multicolumn{2}{|c|}{ TOTAL } \\
\hline & $\mathrm{N}^{\circ}$ & $\%$ & $N^{0}$ & $\%$ & $\mathrm{~N}^{\mathbf{o}}$ & $\%$ \\
\hline Nenhum & 205 & 46,1 & 28 & 30,1 & 233 & 43,3 \\
\hline 1 & 134 & 30,1 & 42 & 45,2 & 176 & 32,7 \\
\hline 2 & 75 & 16,8 & 14 & 15,0 & 89 & 16,6 \\
\hline 3 ou mais & 31 & 7,0 & 9 & 9,7 & 40 & 7,4 \\
\hline TOTAL & 445 & 100,0 & 93 & 100,0 & 538 & 100,0 \\
\hline
\end{tabular}

$\chi^{2}=13,30 ; p=0,0002$.

A Tabela 4.20 também mostra $40,6 \%$ de ignorados no número de filhos tidos mortos, o que é resultado do não preenchimento nem da casela "nenhum", nem do campo quantitativo. Um desempenho bem distinto do visto na Tabela 4.19, onde apenas $3,1 \%$ de não preenchimento da variável número de filhos tidos vivos foram computados. Um treinamento específico dado aos responsáveis pelo preenchimento do formulário corrigiria este problema. Infelizmente, tais dados não puderam ser recuperados, impedindo o uso dessa informação numa tabela comparativa à semelhança da Tabela 4.21 . 
Da análise desta última, uma diferença estatisticamente significativa foi demonstrada, sendo sua causa básica a inversão percentual entre as quantidades "nenhum" e "l" filhos tidos vivos anteriormente.

Uma causa possível, já apontada, é uma falha de registro dos ignorados nas variáveis "filhos tidos" pelo SINASC Padrão. O software simplificado utiliza duas variáveis distintas para cada variável "filhos tidos": uma casela "nenhum" com dois valores possíveis, ou seja, marcada ou desmarcada, e um campo quantitativo. A ausência de preenchimento em ambas identifica o estado de "ignorado" da variável. Já o software padrão só possui o campo quantitativo, portanto, na ausência do preenchimento deste, o digitador precisa inserir no software o valor "99", que foi escolhido pelos programadores do DATASUS como indicativo do estado "ignorado". Em geral, o digitador esquece de preencher com "99" e simplesmente não digita informação alguma no campo em concordância visual com o formulário em suas mãos. Infelizmente, a "informação" “em branco" é interpretada pelos softwares estatísticos como zero, o que aumenta erroneamente a quantidade de eventos "nenhum" para filhos tidos.

Outra possivel causa, agora com origem no SINASC Simplificado, poderia vir de uma interpretação errônea por parte de quem preenche os formulários da quantidade de filhos tidos vivos. $O$ fato desta variável não incluir a atual gestação pode não ter ficado claro para todos, o que poderia alterar todas as proporções à semelhança do que é visto na comparação contida na Tabela 4.21. Mais uma vez, treinamento específico seria a solução. 
Mesmo diante dos problemas enfrentados, o uso de variáveis adicionais ou com maior sensibilidade foi bem sucedido, podendo ser utilizado por municipios que entendam haver utilidade local para tais dados. Isso poderia tanto ser utilizado no sistema simplificado cujo uso foi introduzido neste trabalho, como ser aplicado numa interface padrão alterada, mas com a exportação de dados nos padrões nacionais, conforme a experiência americana (UNITED STATES OF AMERICA 1991). Conforme já mencionado, na revisão da DN americana ocorrida em 1989, o uso de certas variáveis extras foi até mesmo incentivado àqueles que tivessem condição e necessidade de fazê-lo. 


\section{CONCLUSÕES}

Apesar dos obstáculos enfrentados, o desenvolvimento do programa de computador foi bem sucedido e atingiu seu objetivo ao servir de interface complementar ao SINASC Padrão. Seu uso pode não só resgatar nascimentos domiciliares não registrados em cartório como também verificar a efetiva cobertura dos formulários recolhidos nas unidades de saúde e nos cartórios, devendo, para isso, ser acrescentada a variável "Local de Ocorrência".

De fato, a muito pequena quantidade detectada de partos domiciliares no início da pesquisa levou a coleta de dados para nascimentos quaisquer, sem distinção quanto ao "Local de Ocorrência". Esta mudança resultou em outra informação surpreendente: a grande quantidade de DNs resgatadas pelo "SINASC - Interface Simplificada", DNs estas que deveriam constar no banco de dados do SINASC Padrão por terem basicamente ocorrido em unidades de saúde. Das 96 contribuições, somente uma ocorreu em domicilio, apontando para uma falha representativa de $17,7 \%$ de perdas no sistema oficial de coleta do município de Ilhéus. A detecção deste problema através do programa de computador desenvolvido para esta pesquisa apontou não só a falha detectada, mas também um uso não intencionado para a ferramenta no ato de sua criação: instrumento regulador da captação de dados do SINASC Padrão.

Recomenda-se à Secretaria Municipal de Ilhéus um aprimoramento das rotinas de coleta dos formulários de declaração de nascido vivo junto a cartórios e unidades de saúde. 
Outro aspecto importante foi o bom desempenho dos agentes do Programa de Agentes Comunitários de Saúde (PACS) que prontamente se dispuseram a contribuir com a coleta das informações nos bairros de Ilhéus em que atuam. A qualidade das informações adquiridas, apesar de todos os obstáculos descritos, contribui para apontar o "SINASC - Interface Simplificada" como ferramenta viável sob todos os aspectos. O sistema de coleta proposto mostrou-se de fácil aplicação pelos agentes comunitários, sendo possivel reduzir a proporção de não preenchimento com um melhor treinamento dos agentes comunitários.

A introdução de formas mais precisas de obtenção de variáveis no formulário simplificado mostrou-se viável. O nível de preenchimento obtido foi bom para as variáveis data de nascimento da mãe e filhos tidos nascidos vivos e regular para a variável duração da gestação. Contudo, o número de filhos tidos nascidos mortos apresenta problemas nas duas versões.

A diferença estatisticamente significativa na comparação padrão-simplificado da variável "filhos tidos vivos" tem sua causa básica na inversão percentual entre as quantidades "nenhum" e "1" filhos tidos vivos anteriormente. Uma causa possível é uma falha de registro dos ignorados nas variáveis "filhos tidos" pelo SINASC Padrão, sendo esta uma vulnerabilidade conceitual do sistema padrão. Alguma falha conceitual no preenchimento do formulário simplificado é outra possível causa para a diferença estatística. 
A introdução bem sucedida de novas formas de se obter variáveis demonstra a possibilidade de incorporá-las ao SINASC, pois estas se encontram registradas nos prontuários médicos

O SINASC, ao utilizar categorias de duração da gestação, pode estar subestimando os nascidos vivos de pré-termo. Os resultados obtidos que indicam este fato são semelhantes aos dos obtidos em outros estudos (Silva e col. 2001; Crook e col. 2003). Por outro lado, a elevada proporção de nascidos vivos de pré-termo captados pelo SINASC Simplificado sugere que esta população de nascidos vivos possa ter uma maior freqüência de prematuridade. Outra diferença, possivelmente associada à anterior é o menor número de nascidos vivos de mães com pré-natal adequado

O uso da nova interface simplificada acrescenta ao SINASC as vantagens de um sistema único-modular sem perder as vantagens da padronização, embora não tenha sido possível gerar um sistema único por indisponibilidade dos arquivos-fonte do SINASC, o que é lamentável. Com um sistema modular, a informação em nível local pode atender as necessidades do município sem se desviar dos padrões nacionais. Porém, cuidados devem ser tomados na definição destes novos módulos e de suas interfaces para garantir a possibilidade de conversão dos dados colhidos para o formato nacional. Mesmo assim, fica clara a viabilidade da implementação de sistemas de informações modulares, cujas interfaces podem ser definidas a partir das necessidades locais 
Por fim, um programa único no qual estejam implementadas duas ou mais interfaces para atender às diversas necessidades permite fácil acesso ao conjunto dos dados e à sua análise. Diante disso, pode-se vislumbrar um único programa modular centralizando todas as informações de saúde do país, o que dispensaria o uso de técnicas de linkage 


\section{REFERÊNCIAS}

Aho AV e col.. Compiladores: Princípios, Técnicas e Ferramentas. Editora LTC. $1^{\text {a }}$ Edição. 1995

Almeida MF, Mello Jorge MHP. O uso da técnica de "Linkage" de sistemas de informação em estudos de coorte sobre mortalidade neonatal. Revista de Saúde Pública 30:141-147, 1996.

Almeida MF. O Perfil dos Nascidos no Brasil 1994 a 1997. São Paulo; 2000.

Brasil. Lei n.6015, de 31 de dezembro de 1973. Dispõe sobre os registros públicos e dá outras providências. Título II - Capítulo IV. Senado Federal do Brasil. $<\mathrm{http}: / /$ wwwt.senado.gov.br/legbras/ $>$ [2003 Jan 9]

Brasil. Lei n.6216, de 30 de junho de 1975. Altera a Lei n.6015, de 31 de dezembro de 1973, que dispõe sobre registros públicos. Título II - Capítulo IV. Senado Federal do Brasil. <http://wwwt.senado.gov.br/legbras/> [2003 Jan 9]

Brasil. Sociedade Civil Bem-Estar Familiar no Brasil, BEMFAM. Pesquisa Nacional Sobre Demografia e Saúde 1996. Programa de Pesquisas de Demografia e Saúde (DHS) Macro International Inc. Março; 1997a.

Brasil. Ministério da Saúde. Informe Epidemiológico do SUS. Ano VI, $n^{\circ} 4$ Out/Dez - 1997b.

Brasil. Ministério da Saúde. Guia de Vigilância Epidemiológica, capítulo 3 Coleta de Dados e Informações. <www.funasa.gov.br/epi/epido.htm> [2001 Jul 5]

Crook PO e col. Avaliação da Qualidade das Informações do SINASC. Faculdade de Saúde Pública - USP; 2003. 
DATASUS - Tecnologia da Informação a Serviço do SUS. Ministério da Saúde. Informações de Saúde. Brasil. <http://tabnet datasus.gov.br/tabnet/tabnet.htm> [2003 Jan 27]

Date CJ. Introdução a Sistemas de Bancos de Dados. Editora Campus, 1991

Elmasri R, Navathe SB. Fundamentals of Database Systems. Benjamin-Cummings Publishing, 2nd. Edition, 1994.

Feuer AR, Gehani NH. A Comparison of the Programming Languages $\mathbf{C}$ and Pascal - Part I: Language Concepts. Bell Labs internal memorandum; Setembro, 1979.

Feuer AR, Gehani NH. A Comparison of the Programming Languages $C$ and Pascal - Part II: Program Properties and Programming Domains. Bell Labs internal memorandum; Fevereiro, 1980

Gunnerson E. Introdução à programação em C\#. Editora Ciência Moderna. $1^{\text {a }}$ Edição. 2001.

Heuser CA. Projeto de Banco de Dados. Sagra Luzatto, 1998.

Ilhéus. Prefeitura Municipal. Plano Municipal de Saúde Quadriênio - 1998-2001. Ilhéus-Ba, 1998.

Kale PL. Primeira avaliaçäo do Sistema de Informaçöes sobre Nascidos Vivos no Município de Niterói. Cad. saúde coletiva (Rio de Janeiro);5(1):53-64, jan.-jun. 1997.

Kernighan BW. Why Pascal is Not My Favorite Programming Language. AT\&T Bell Laboratories, Murray Hill, New Jersey 07974; Abril, 1981 
Korth HF, Silberschatz A. Sistemas de Bancos de Dados. Makron Books, 2a. edição, 1994.

Laurenti R e col. Estatísticas de saúde. São Paulo: EPU/EDUSP; 1985.

Maia MAC. Caracterização dos nascidos vivos hospitalares no primeiro ano de implantação do Subsistema de Informação sobre Nascidos Vivos, em município de Minas Gerais, Brasil, 1996. Revista de Saúde Pública 31:581-585; 1997.

Mateti P. Pascal versus C: A Subjective Comparison. Language Design and Programming Methodology Symposium; Springer-Verlag, Sydney, Australia; Setembro, 1979.

Mello Jorge MHP. Sub-registro dos eventos vitais. Revista de Saúde Pública, $17: 148-151 ; 1983$

Mello Jorge MHP. Registros dos eventos vitais: sua importância em saúde pública. Série Divulgação no 5 . São Paulo: Centro da OMS para a Classificação de Doenças em Português; 1990.

Mello Jorge MHP e col. O Sistema de Informação sobre Nascidos Vivos SINASC. Série Divulgação n 7 . São Paulo: Centro da OMS para a Classificação de Doenças em Português/Núcleo de Estudos em População e Saúde; 1992.

Mello Jorge MHP, Gotlieb SLD, Sobbol MLMS, Almeida MF, Latorre MRDO. Avaliação do Sistema de Informação sobre Nascidos Vivos e o uso de seus dados em epidemiologia e estatisticas de saúde. Revista de Saúde Pública 27(Supl); 1993.

Mello Jorge MHP, Gotlieb SLD, Oliveira H. O Sistema de Informação sobre 
Nascidos Vivos: primeira avaliação dos dados brasileiros. Informe Epidemiológico do SUS, 2:15-48; 1996.

Mello Jorge MHP e col. Análise dos registros de nascimentos vivos em localidade urbana no Sul do Brasil. Rev. Saúde Pública v. 31 n. 1 São Paulo; Fevereiro 1997.

Mello Jorge MHP, Gotlieb, SLD. O sistema de informaçäo de atençäo básica como fonte de dados para os sistemas de informaçöes sobre mortalidade e sobre nascidos vivos. Informe epidemiológico do SUS;10(1):7-18, jan.-mar. 2001

Moraes NL de A. Estudo sobre a importância dos fatores que podem condicionar a deficiência dos registros de nascimento. Rev. Serv. Saúde Pública, 2:743-74; 1949.

Noronha CP, Silva RI, ThemeFilha MM. Concordância de dados das Declarações de Óbitos e de Nascidos Vivos para a mortalidade neonatal no município do Rio de Janeiro. Informe Epidemiológico do SUS VI(4):57-65; 1997

Oliveira H, Pereira IPA. Estatísticas de Mortalidade e Nascidos Vivos: considerações sobre principais problemas. Informe Epidemiológico do SUS VI(3): 15-19; 1997.

Organização Pan-Americana de Saúde. Compatibilização de Sistemas e Bases de Dados (CBD) da Rede Integrada de Informações para a Saúde (RIPSA) Informe Final. Outubro; 1997.

Ortiz L. Descentralização e a municipalização da saúde. Atualizado em 10/10/2002. <http://www.comciencia.br/reportagens/ppublicas/pp06.htm> [2002 
Dez 23]

Portela MHRB. Sub-registro de nascimentos vivos em Piripiri-Piaui. Rev. Saúde Pública, 23:493-501; 1989.

Porto Alegre. Secretaria Municipal de Saúde. Relatório preliminar do sistema de informaçäo sobre nascidos vivos: SINASC - 1994. Porto Alegre; CEDIS; ago. 1995.

Ramakrishnan R. Database Management Systems. McGraw-Hill, 1998.

Repullo Jr R. A municipalização das ações de saúde do trabalhador no Sistema Único de Saúde do Brasil. São Paulo; Brasil, 2001.

Rodrigues CS, Magalhães Jr. HM, Evangelista PA, Ladeira RM, Laudares S. Perfil dos nascidos vivos no município de Belo Horizonte, 1992-1994. Cadernos de Saúde Pública 13:53-57; 1997

Rosado $P$. Aspectos do registro civil de nascimento em uma cidade do interior do Amazonas, 1938-1947. Rev. Serv. Saúde Pública, 2: 772-92; 1949

Saade MJ. Verificação estatística do grau de deficiência do registro de nascimento. Rev. Serv. Saúde Pública, 1:449-67; 1947.

Santa Helena ET., Wisbeck J. Implantação do SINASC e Perfil dos Nascidos Vivos de Blumenau, 1994-1997. IESUS, VII (3), Jul/Set; 1998

Scorzelli Jr. A. Coleta de dados vitais em pequenas localidades. Rev. Serv. Saúde Pública, 1:397-432; 1947.

SIAB. Manual do Sistema de Informação de Atenção Básica. Secretaria de Assistência à Saúde, Coordenação de Saúde da Comunidade. Brasília: Ministério 
da Saúde, 1998.

Silberschatz A e col. Operating Systems Concepts. Addison-Wesley, 5th ed., 1998.

Silva, AAM e col. Avaliaçäo da qualidade dos dados do sistema de informaçöes sobre nascidos vivos em 1997 - 1998. Rev. saúde pública;35(6):508-514, dez. 2001.

Souza RKT, Gotlieb SLD. Sub-registro de nascimento vivos hospitalares em área urbana da região sul do Brasil, em 1989. Rev. Saúde Pública, 27: 177-84; 1993.

Souza RKT. Mortalidade infantil e sub-registro de nascidos vivos no Município de Maringá-PR, em 1989. Säo Paulo; 1992.

Souza RCA. Diagnóstico Sócio-sanitário-participativo do bairro Nossa Senhora da Vitória e proposta de intervenção com base em problemas priorizados. Ilhéus-Ba, 2000.

Springer A. A Comparison of Language C and Pascal. IBM Technical Report G320-2128, Cambridge Scientific Center; Agosto, 1979.

United States of America. Centers for Disease Control / National Center for Health Statistics. The 1989 Revision of the U.S. Standard Certificates and Reports. Vital and Health Statistics, Series 4, No. 28, June 1991.

Waldman EA. Vigilância em Saúde Pública. São Paulo, 1998. 


\section{ANEXO I - A DECLARAÇÃO DE NASCIDO VIVO - DN}

República Federativa do Brasil Ministerio da saúde
a via - Secretario de Sádude

Declaraçäo de Nascido VNo ma mo m

m cantón

1 育

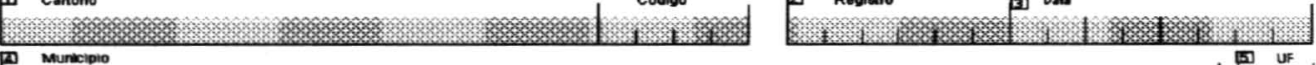

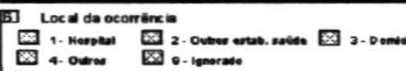

II

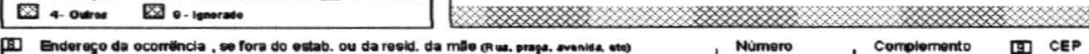

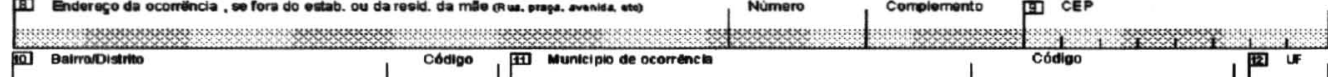

(3) Nome da mase (A) RC

$\frac{1}{n}$

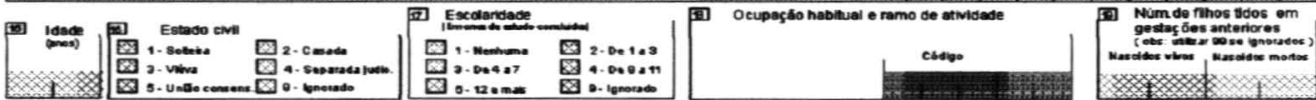
Residoincia do mán

Nomero

Complemento :

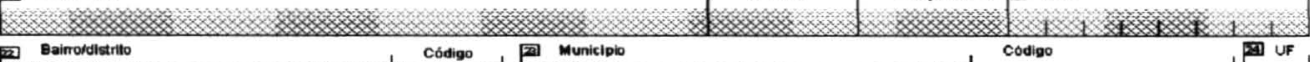

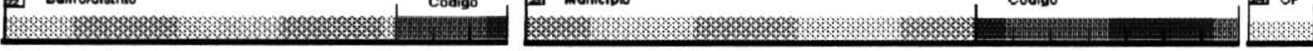

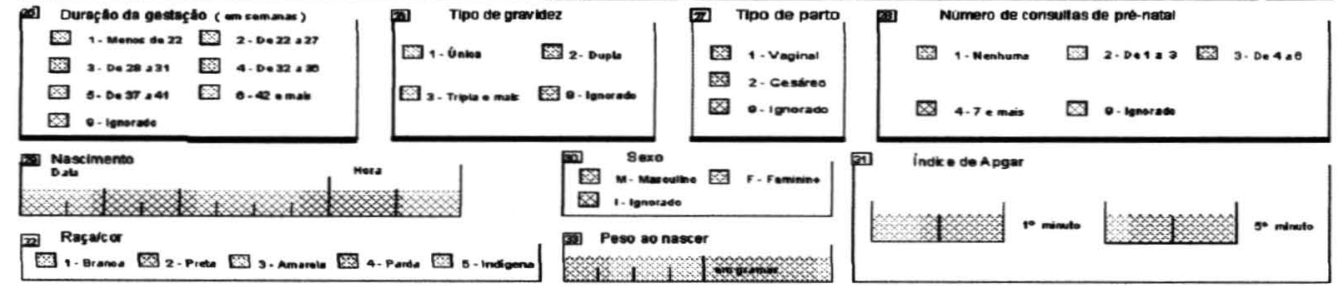

$\mathbf{V}$

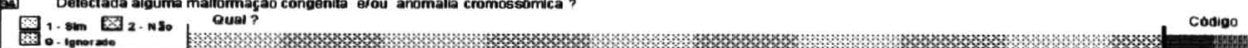

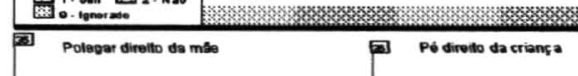

ท

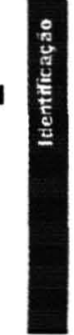
\%

VII

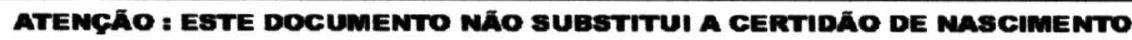
O Registro de Nascimento é obrigatório por lei Para registrar esta criança, o pai ou responsável deverá levar este documento ao cartório de registro civil. 


\section{ANEXO II - A DN SIMPLIFICADA}

\begin{tabular}{|lll|}
\hline Declaração de Nascido Vivo - Simplificada & n.0001 & Pesquisa com apoio do PACS/PSF \\
\hline
\end{tabular}

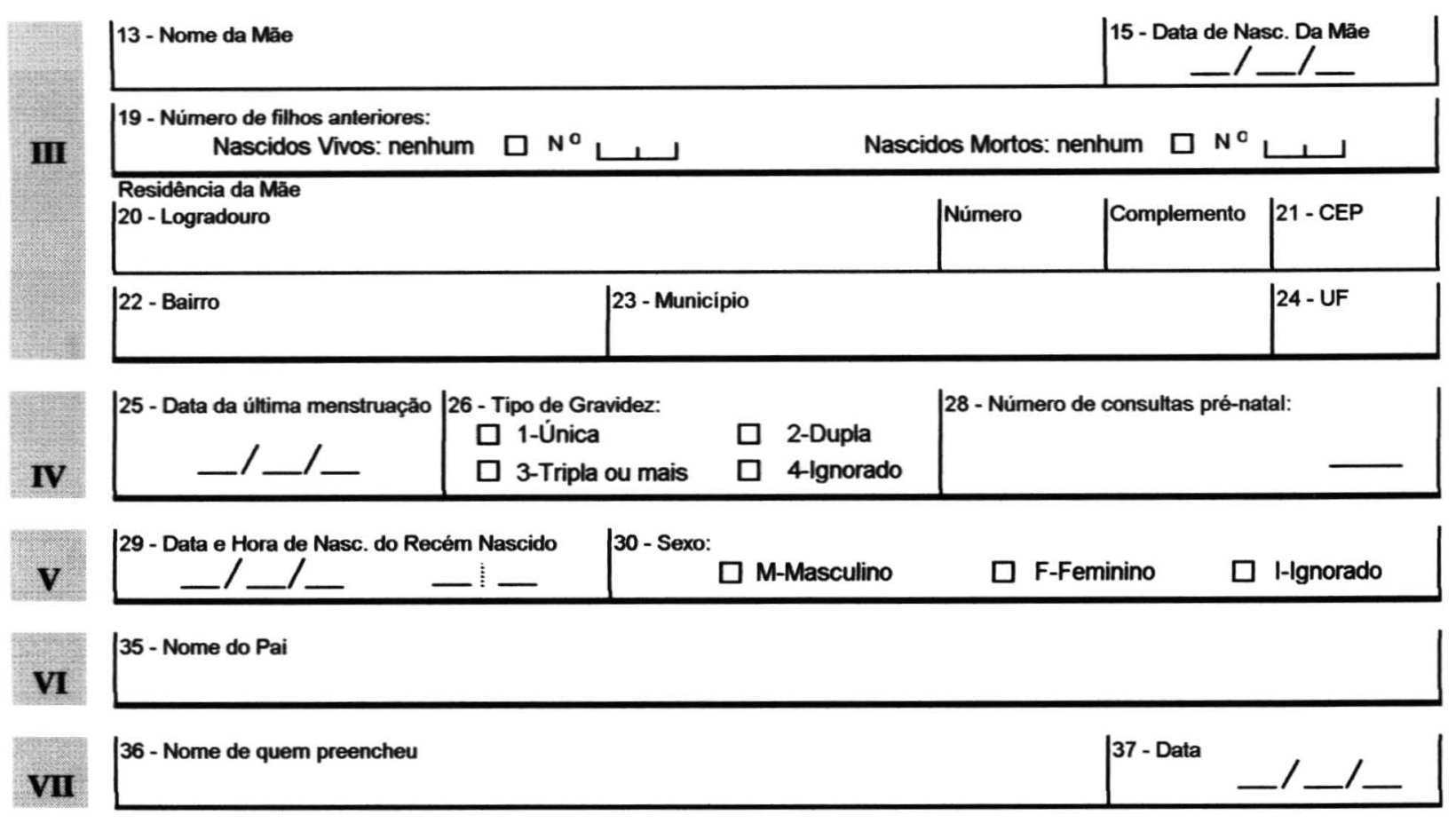




\title{
ANEXO III - O MANUAL DE PREENCHIMENTO DA DN \\ SIMPLIFICADA
}

\author{
MANUAL DE INSTRUÇÕES \\ PARA PREENCHIMENTO DA \\ DECLARAÇÃO DE NASCIDOS VIVOS - SIMPLIFICADA
}

Produzido para instruir o preenchimento de formulário de pesquisa.

Baseado no manual produzido originalmente pelo Ministério da Saúde.

\section{I - Apresentação}

Este manual foi adaptado a partir do "Manual de Instruçōes para o Preenchimento da Declaração de Nascido Vivo" do Ministério da Saúde. Os formulários simplificados que são alvo deste manual fazem parte de um projeto de pesquisa que visa melhorar a qualidade e a quantidade de informação disponível sobre nascidos vivos no Brasil.

O objetivo inicial é que este seja utilizado pelos profissionais do PACS / PSF do municipio de Ilhéus para auxiliar no preenchimento de tais formulários, gerando material que será alvo de análise de uma tese de doutorado em Saúde Pública pela Universidade de São Paulo pelo professor Fernando Flores Santos Ribeiro.

\section{II - Instruções Gerais:}

O formulário alvo deste manual deve ser preenchido para cada nascido vivo das famílias visitadas pelo PACS / PSF, nascimentos estes ocorridos entre os dias 01/03/2002 e 31/05/2002, SOMENTE para os nascimentos ocorridos no domicílio, e que não receberam assistência médicohospitalar logo após a sua ocorrência.

Apenas uma via deve ser preenchida para cada nascido vivo. Em caso de nascimento de gêmeos ou mais, deve ser preenchida uma via para cada um deles.

Preencher com letra de forma (legivel), com caneta esferográfica.

Evitar rasurar o formulário. Caso isso ocorra a ponto de dificultar a leitura da informação, anular e preencher outro.

Preencher todos os campos da Declaração. Evitar deixar caselas ou espaços em branco. Colocar "ignorado" ou traço (一) quando a obtenção da informação for impossivel 


\section{III - Instruções Específicas:}

\section{MódULO III - DADOS DA MÃE:}

13- Nome - colocar o nome completo, por extenso. Sempre que possivel solicitar um documento de identificação para se evitar erros no preenchimento do nome da mãe.

15- Data de Nascimento (dia/mês/ano): registrar o dia, mês e ano de nascimento da mãe.

19- Número de Filhos Anteriores: colocar o número de filhos anteriores tidos por essa mãe, subdividindo em nascidos vivos e nascidos mortos. Se não houver, marcar a opção nenhum. Atenção: não incluir a criança da atual gestação.

20- Logradouro: registrar o endereço completo da mãe, com nome da rua e número. Caso a mãe não saiba, deve-se perguntar um ponto de referência na comunidade em que reside (por exemplo: perto de uma igreja, praça, farmácia, etc.).

21- Bairro: registrar o bairro onde a rua fica situada se for domicílio urbano. Se for rural. perguntar a localização (fazenda, gleba, etc.)

22- CEP: registrar o código de endereçamento postal da mãe.

23- Municipio: registrar o município onde se localiza o endereço da mãe e código.

24- UF: registrar a sigla da UF a qual o município pertence.

\section{Módulo IV - Gestação e Parto:}

25- Data da última menstruação: se a mãe não lembrar a data exata, registrar ao menos data aproximada ou somente o mês e ano.

26- Tipo de Gravidez: 1-Única, 2-Dupla, 3-Tripla ou mais, 9-Ignorado;

28- Número de consultas pré-natal: registrar a quantidade de consultas no caso de terem sido realizadas. Registrar zero (0) para o caso de não terem sido realizadas. Quando for impossível conhecer esse valor, colocar um traço ( - ).

\section{MódULo V - Dados do RecÉm NASCIDO:}

29- Data e Hora de Nascimento do Recém Nascido: registrar nos espaços correspondentes, a data do nascimento: dia, mês, ano e a hora precisa (com minutos) em que ocorreu o parto. Se não lembrar a hora exata, registrar ao menos a hora aproximada.

30- Sexo: M-Masculino, F-Feminino, I-Ignorado;

Módulo VI - DADOS DO PAI:

35- Nome do Pai;

Módulo VII - PREenchimento:

36- Nome de quem preencheu;

37-Data de preenchimento. 